NIPER-506

Distribution Category UC-122

\title{
THE EFFECT OF ALKALINE ADDITIVES ON THE PERFORMANCE OF SURFACTANT SYSTEMS DESIGNED TO RECOVER LIGHT CRUDE OILS
}

$$
\text { NIPER- }-506
$$

Topical Report

DE91 002226

By

T. R. French

C. B. Josephson

D. B. Evans

February 1991

Work Performed Under Cooperative Agreement No. FC22-83FE60149

\author{
Prepared for \\ U.S. Department of Energy \\ Assistant Secretary for Fossil Energy \\ Jerry Casteel, Project Manager \\ Bartlesville Project Office \\ P.O. Box 1398 \\ Bartlesville, OK 74005
}

Prepared by

IIT Research Institute

National Institute for Petroleum and Energy Research

P. O. Box 2128

Bartlesville, OK 74005 


\section{TABLE OF CONTENTS}

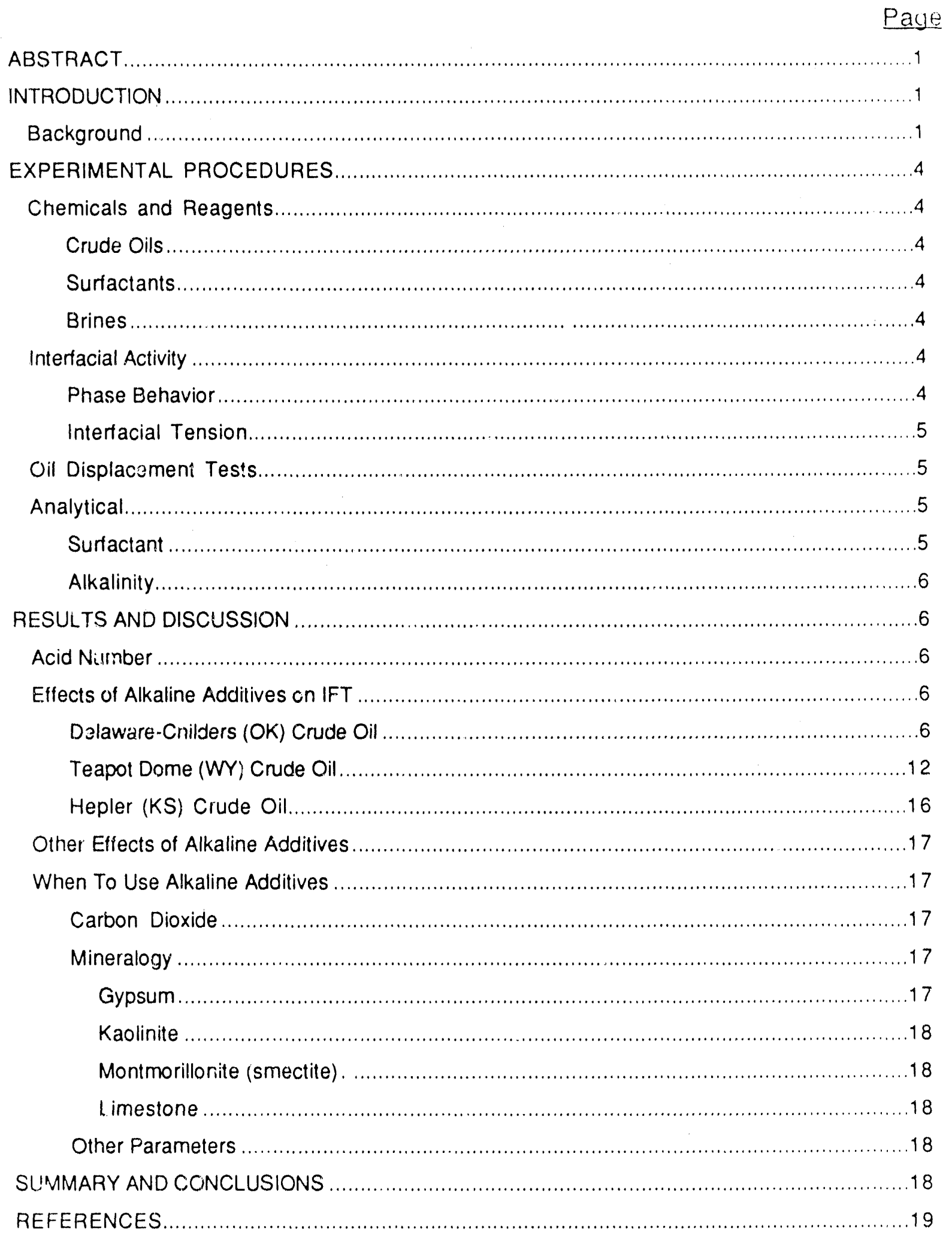




\title{
TABLE OF CONTENTS -- Continued
}

\begin{abstract}
Page

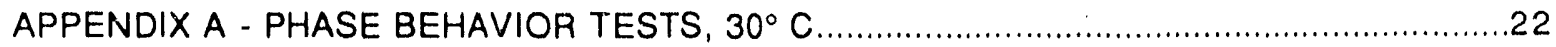

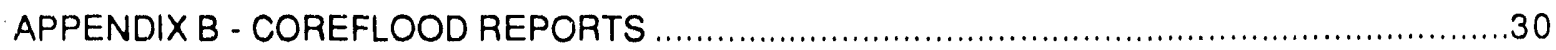

TABLES

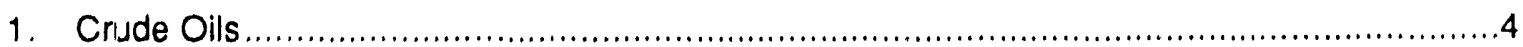

2. Corefloods conducted with surfactant formulations that contain alkaline additives.............12

3. Dynamic interfacial tension of surfactant formulations that contain alkaline additives............15

\section{ILLUSTRATIONS}

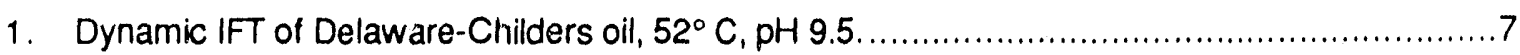

2. Dynamic IFT of Delaware-Childers oil and $0.1 \%$ Petrostep $B-100$ anionic surfactant, $52^{\circ} \mathrm{C}$, $\mathrm{pH} 6.3$.

3. Dynamic IFT of Delaware-Childers oil and $0.2 \%$ Petrostep B-100 anionic surfactant, $30^{\circ}$ $\mathrm{C}, \mathrm{pH} 9.5$.

4. Dynarnic IFT of Delaware-Childers oil and 0.2\% Neodol 25-9 (ethoxylated alcohol) surfactant, $30^{\circ} \mathrm{C}, \mathrm{pH} 9.5$

5. Dynamic IFT of Delaware-Childers oil and $0.2 \%$ Petrostep $\mathrm{B}-100$ anionic surfactant, $30^{\circ} \mathrm{C}$, $\mathrm{pH} 8.3$.

6. Dynamic Initial IFT values measured with Delaware-Childers oil and $0.2 \%$ Petrostep B-100 anionic surfactant, $30^{\circ} \mathrm{C}, \mathrm{pH} 6.3$ and $\mathrm{pH} 8.3$. .10

7. Comparison of Dynamic IFT of Delaware-Childers oil and Petrostep B-100 anionic surfactant at two alkali concentrations, $30^{\circ} \mathrm{C}, \mathrm{pH} 8.3$.

8. Effect of polymer on the Dynamic IFT of Delaware-Childers oil and $0.2 \%$ Petrostep B-100, anionic surfactant, $30^{\circ} \mathrm{C}, \mathrm{pH} 8.3$

9. Changes in oil saturations during chemical floods conducted with surfactant formulations that contain alkaline additives.

10. Effluent analysis for chemical flood DCNS-1.

11. Dynamic IFT of Teapot Dome oil and $0.1 \%$ Petrostep B-100 anionic surfactant, $52^{\circ} \mathrm{C}, \mathrm{pH}$

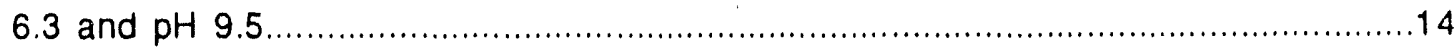

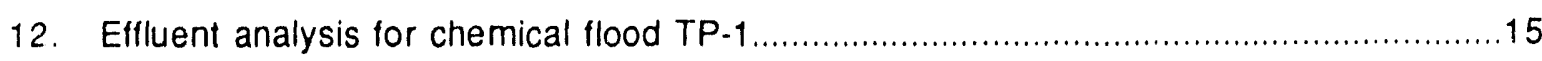

13. Dynamic initial IFT values measured with Hepler oil and Petrostep B-120 anionic surfactant, $27^{\circ} \mathrm{C}, \mathrm{pH} 6.3$ and $\mathrm{pH} 9.5$ 


\title{
THE EFFECT OF ALKAL:: : ADDITIVES ON THE PERFORMANCE OF SURFACTANT SYSTEMS DESIGNED TO RECOVER LIGHT CRUDE OILS
}

\author{
By T. R. French, C. B. Josephson, and D. B. Evans
}

\begin{abstract}
Surfactant flooding is flexible because of the ability 10 optimize formulations for a wide range of reservoir conditions and crude oil types. The objective for this work was to determine if the addition of alkaline additives will allow the design of surfactant formulations that are effective for the recovery of crude oil, wlile, at the same time, maintaining the surfactant concentration at a mu, 1 lower level than has previously been used for micellar flooding. Specifically, the focus of the work was on light, midcontinent crudes that typically have very low acid contents. These oils are typical of much of the midcontinent resource.
\end{abstract}

The positive effect of alkaline additives on the phase behavior of surfactant formulations and acidic crude oils is well known. The extension to nonacidic and slightly acidic oils is not obvious. Three crude oils, a variety of commercial surfactants, and several alkaline additives were tested. The oils had acid numbers that ranged from 0.13 , which is quite low, to less than $0.01 \mathrm{mg} \mathrm{KOH} / \mathrm{g}$ of oil.

Alkaline additives were found to be very effective in recovering Delaware-Childers $(O K)$ oil at elevated temperatures, but much less effective at reservoir temperatures. Alkaline additives were very effective with Teapot Dome (WY) oil. With Teapot Dome oil, surfactant/alkali systems produced ultralow IFT values and recovered $60 \%$ of the residual oil that remained after waterlooding. The effect of alkaline additives on recovering Hepler (KS) oil was minimal.

The results of this work indicate that alkaline additives do have merit for use in surfactant flooding of low acid crude oils; however, no universal statement about applicability can be made. Each oil behaves differently, with this treatrnent, and the effect of alkaline additives must be determined (at reservoir conditions) for each oil.

\section{INTRODUCTION}

\section{Backaround}

Of the various enhanced oil recovery (EOR) technologies, surfactant flooding is the most flexible method because of the ability to optimize formulations for a wide range of ressrvoir conditions and crude oil types. By varying the type and concentration of surfactant and cosurfaciant, formulations with optimal displacement efficiencies can be designed to recover crude oil from a reservoir with a specific salinity, brine composition, temperature, and rock mineralogy. In 1984, the National Petroleum Council reported that chemical flooding has the potential to recover up to 2.5 billion bbl of crude oil in the United States. ${ }^{1}$ 
Several chemical flooding field pilot tests have produced significant amounts of incremental oil and have been technically, but not economically, successful. The goal of the NIPER research program in su'factant flooding is to develop systems that are cost-effective for recovering light crude oils. The focus has been on (1) identifying surfactant formulations or methods that are more cost effective than those currently available and (2) mitigating the problems that have adverse effects on the performance and economics of suriactant flooding processes.

Midterm research and development efforts at NIPER have focused on screening various novel surfactants to identify those that are tolerant to changes in salinity and divalent ion concentration and are applicable over wider temperature ranges. Some surfactants are less expensive thail others; however, surfactant is an expensive component in all micellar formulations because of the large quantity that must be injected into a reservoir. The selection of multicomponent formulations that minimize chromatographic separation and the use of relatively inexpensive sacrificial agents have been investigated for the reduction of losses of surfactant. Another way to reduce chemical costs is to reduce the concentration of the surfactant.

In early research on surfactant flooding, a search was made for cost-effective surfactants that were capable of reducing interfacial tension (IFT) and were stable at typical reservoir brine concentrations and temperatures. Petroleum sulfonates were usually the class of surfactant that was investigated, primarily because they were stable at reservoir temperatures and relatively inexpensive. Even though petroleum sulfonates are relatively inexpensive, the economics of field pilots are adversely impacted by the large amounts of surfactant required. Surfactant formulations capable of producing ultralow IFT values typically contain 3 to $5 \%$ concentrations of active surfactants.

Research'ss have been motivated to design surfactant formulations that will produce ultralow IFT values with much lower surfactant concentrations. Reducing the concentration of surfactant that must be injected to maintain effective displacement for a distance into a reservoir will make a direct improvement in the economics of applying the process. With these systems, possible losses of the surfactant in a reservoir by adsorption and phase trapping become more important.

Addition of alkaline additives to surfactant formulations has been found to be beneficial by reducing losses of surfactant and polymer, reducing concentrations of divalent cations that cause losses of surfactant by partitioning and precipitation, and by affecting interfacial properties. The effects of alkaline/surfactant formulations on heavy, acidic oil have been known for some time. ${ }^{2-6}$ Recent research has shown that weakly alkaline adaitives to surfactarit formulations may also be effective for the recovery of light crude oils, and with greatly reduced concentrations of surfactant. ${ }^{7-9}$ 
Further research on interactions between complex components of crude oils and both alkaline and surfactant chemicals is needed to determine how best to utilize the benefits obtained by adding alkaline additives to surfactant formulations. This report addresses the use of surfactant/alkaline formulations for recovery of light crude olls.

In 1984, NIPER began testing weak alkaline agents, such as sodium bicarbonate and sodium carbonate, for their ability to mobilize residual oil. The use of weak alkalis was shown to avoid or reduce some of the adverse reactions that usually occur between reservoir rock and strong alkalis. The lower $\mathrm{pH}$ alkalis reacted with acidic components of crude oils to produce surfactants in situ, but the amourt of natural surfactants extracted from the crude oil were less than that obtained with stronger alkaline agents; therefore, the reduction in IFT was also less.

During attempts to increase the amount of oil solubilized, it was discovered that very low concentrations of synthetic surfactants could be added to an alkaline slug and be very effective in oil recovery. ${ }^{10}$ It was also observed that alkaline conditions resulted in lower losses of surfactant by precipitation and adsorption. Most of the research was conducted with heavy oils that contained significant amounts of acidic components. In these experiments, the total ac' 1 number, which is an indication of the amount of acidic components in an oil, was usually above $1.0 \mathrm{mg} \mathrm{KOH} / \mathrm{g}$ of oil. During the initial work, it was assumed that an appreciable acid number would be necessary for alkaline additives to have a significant impact on the lowering of IFT by a surfactant formulation. It was realized, however, that some of the other effects of alkaline additives would be beneficial in reservoirs that contain non-acidic oils.

Studies with an acidic oil and surfactant/alkaline formulations showed that a very low initial IFT was predominantly the result of natural surfactants generated by reaction with alkaline agents, and sustained low IFT was primarily the result of synthetic surfactant. ${ }^{2}$ A mixture of synthetic surfactant and alkali produced lower IFT and sustained low IFT longer than either reactant alone. It was also observed that the extraction of acids from acidic crude oils by alkalis appeared to render the oil more interfacially reactive to synthetic surfactant. Many midcontinent crudes have very low acid numbers, and this latter observation led to tests with oils that have low acid numbers.

The behaviors of three light midcontinent crude oils and surfactant mixtures that contain alkaline additives are described in this report. The three light oils have acid numbers that range from 0.01 to 0.13 $\mathrm{mg} \mathrm{KOH} / \mathrm{g}$ of oil, typical of many midcontinent reservoirs, and the results are compared with the behavior of a representative acidic crude oil. The work with the acidic crude was previously performed under another project. Finally, suggestions are made about the use of alkaline additives for recovery of light crude oils. 


\section{EXPERIMENTAL PROCEDURES \\ Chemicals and Reagents \\ Crude Olls}

The crude oils were selected to represent light midcontinent oils with a range of acid contents. The crude oils were obtained from Delaware-Childers (OK), Teapot Dome (WY), and Hepler (KS) oil fields. The crude oil properties are summarized in table 1.

\section{Surfactants}

Three surfactants, one nonionic and two anionic, were used in the experiments. Petrostep B-100 is a medium-molecular-weight alkyl aryl sodium sulfonate produced by Stepan Company. It is designed for use in low-concentration surfactant flooding. Petrostep B-120 is a low-molecular-weight sodium sulfonate manufactured by the same company. Neodol 25-9 is a nonionic ethoxylated alcohol produced by Shell Chemical Company. It contains, on average, 9.2 ethylene oxide groups per mole.

\section{Brines}

The synthetic brines contained sodium chloride. The alkaline additives were sodium bicarbonate and mixtures of sodium bicarbonate with sodium carbonate. Compositions of brines and chemical formulations are given in appendix $B$.

\section{Interfacial Activity}

\section{Phase Behavior}

Equal volumes $(4 \mathrm{~mL}$ ) of oil and aqueous phase were sealed in $10-\mathrm{mL}$ graduated ampoules, and the samples were placed in a temperature-controlled oven. Observations were made after 1 day. The samples were observed at that time and evaluated. The samples were then evaluated while boing shaken. Finally, the samples were evaluated again after 1 more day. Observations while shaking provided information about the type of emulsion formed (oil-in-water or water-in-oil), the ease of emulsification, the stability of the emulsion (while shaking), and the amount (qualitative) of oil emulsified. The final evaluation ( 1 day after shaking) provided additional data on emulsion stability.

TABLE 1 - Crude oils

\begin{tabular}{ccc}
\hline Oil & Gravity, ${ }^{\circ}$ API & Total Acid Number, mg KOH/g \\
\hline & & \\
Delaware - Childers & 33.0 & 0.13 \\
Teapot Dome & 34.1 & 0.01 \\
Hepler & 26.1 & $<0.01$ \\
\hline
\end{tabular}


The emulsions formed were evaluated according to the following criteria:

Emulsion quality

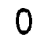

1

2

3

4

\section{Criteria}

No visible emulsification.

Black emulsion.

Brown emulsion that changes to black while shaking.

Brown emulsion.

Brown emulsion containing $>90 \%$ of the oil in the sample.

Higher values of "emulsion quality" correlate with greater interfacial activity and nearness to optimal conditions. This visual method for determining optimal salinity for producing interfacially active systems is only slightly different from visual methods used by others. ${ }^{11-12}$

\section{Interfacial Tension}

Interfacial properties of selected systems were measured with a controlled-temperature, spinning drop interfacial tensiometer. The transient IFT behavior of nonequilibrated samples was monitored over a time interval of several hours.

\section{Oil Displacement Tests}

Unfired, oil-free Berea sandstone cores $(25.4 \times 3.8 \mathrm{~cm})$ were saturated with brine and mounted in Hassler-type coreholders. The cores were oil flooded to residual water saturation and then waterflooded to residual oil saturation before starting the chemical flood. Injection strategies for the corefloods are given in appendix $R$. Frontal advance rates were approximately $1 \mathrm{ft} / \mathrm{d}$, providing a core residence time of about 0.8 day.

Native-state cores from Delaware-Childers $(O K)$ field were stored under brine, then horizontal core plugs $(3.8 \mathrm{~cm}$ diameter) were cut. Sufficient core plugs were butted together (without filler between plugs) to produce cores about $25 \mathrm{~cm}$ long. The cores were then waterflooded before starting the chemical flood. Frontal advance rates were approximately $1 \mathrm{ft} / \mathrm{d}$.

\section{Analytical \\ Surfactant}

The analytical methods used for measurement of surfactant concentration were two-phase titration and HPLC. The two-phase titration was described by Rosen and Goldsmith, ${ }^{13}$ and the HPLC procedure is very similar to that described by Hofman and Angstadt. ${ }^{14}$ The wavelength used for absorbance 
measurement of Petrostep B-100 surfactant was $222 \mathrm{~nm}$, which is very close to the wavelength selected by Hofman and Angstadt.

\section{Alkalinity}

Effluent samples were collected in $5-\mathrm{mL}$ increments and centrifuged before the volume of oil collected was determined. The aqueous phase was then separated and analyzed for alkalinity by titration to $\mathrm{pH} 4$ with $0.1 \mathrm{~N} \mathrm{HCl}$.

\section{RESULTS AND DISCUSSION \\ Acid Number}

The positive effect of alkaline additives on the phase behavior of surfactant formulations and acidic crude oil is well known, and the extension to non-acidic and slightly acidic oils is not obvious. The acid number of a crude oil, expressed as milligrams of potassium hydroxide required to neutralize the acids in 1 gram of the oil, is an important parameter for traditional alkaline flooding; however, a detailed study of 24 alkaline field projects failed to show a correlation between oil acid number and project success. ${ }^{15}$ The fucus of this work is the effect of alkaline additives in surfactant formulations designed to recover light, midcontinent crudes that typically have very low acid contents.

\section{Effects of Alkallne Additlves on IFT \\ Delaware-Childers (OK) Crude OII}

Crude oil from Delaware-Childers (OK) oil field was used for testing the use of alkaline additives in surfactant formulations. The oil is $33^{\circ} \mathrm{API}$ gravity and has an acid number of $0.13 \mathrm{mg} \mathrm{KOH} / \mathrm{g}$ oil, a very low acid number. In prior work, it was demonstrated that, under certain conditions, low values of IFT that are favorable to the mobilization of residual oil could be achieved between Delaware-Childers crude oil and formulations that contain alkaline additives and dilute concentration of synthetic surfactants. ${ }^{3,7}$ This behavior was demonstrated during a series of tests conducted with several crude oils at $52^{\circ} \mathrm{C}$. The results are shown in figures 1 and 2.

The Delaware-Childers oil is slightly acidic and relatively unreactive to alkali. Figure 1 shows that alkali alone produced only a small reduction in IFT. The addition of $0.1 \%$ Petrostep B-100 ál., ic surfactant to the alkali resulted in a very rapid lowering of IFT to a low value, which was sustained for a long period. This behavior is very similar to the behavior observed previously with acidic oils. The minimum IFT of $2.9 \mu \mathrm{N} / \mathrm{m}$ for the combination of synthetic surfactant and alkali was much lower than was achieved with either component alone. The IFT behavior for $0.1 \%$ surfactant alone is shown in figure 2 . The results with the Delaware-Childers crude indicated that even for crude oil with very low acid number, the combination of alkali and a low concentration of synthetic surfactant can produce very low IFT values. 


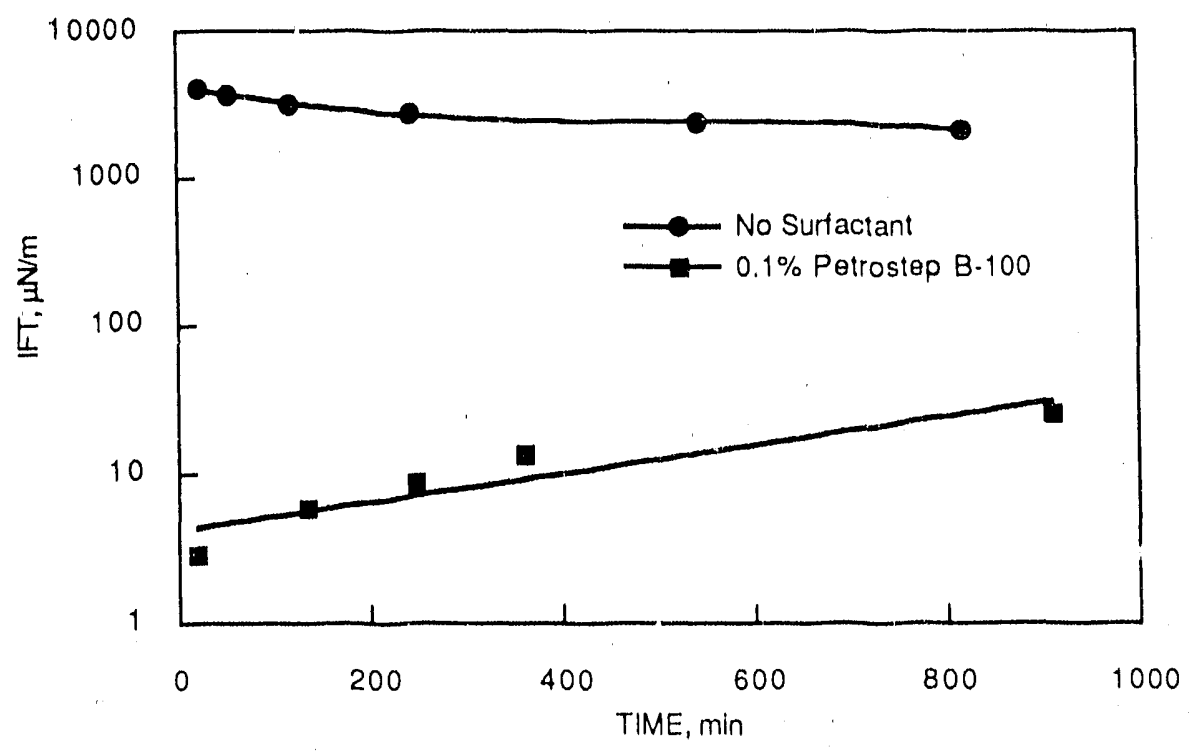

FIGURE 1. - Dynamic IFT of Delaware-Childers oil, $52^{\circ} \mathrm{C}, \mathrm{pH} 9.5$.

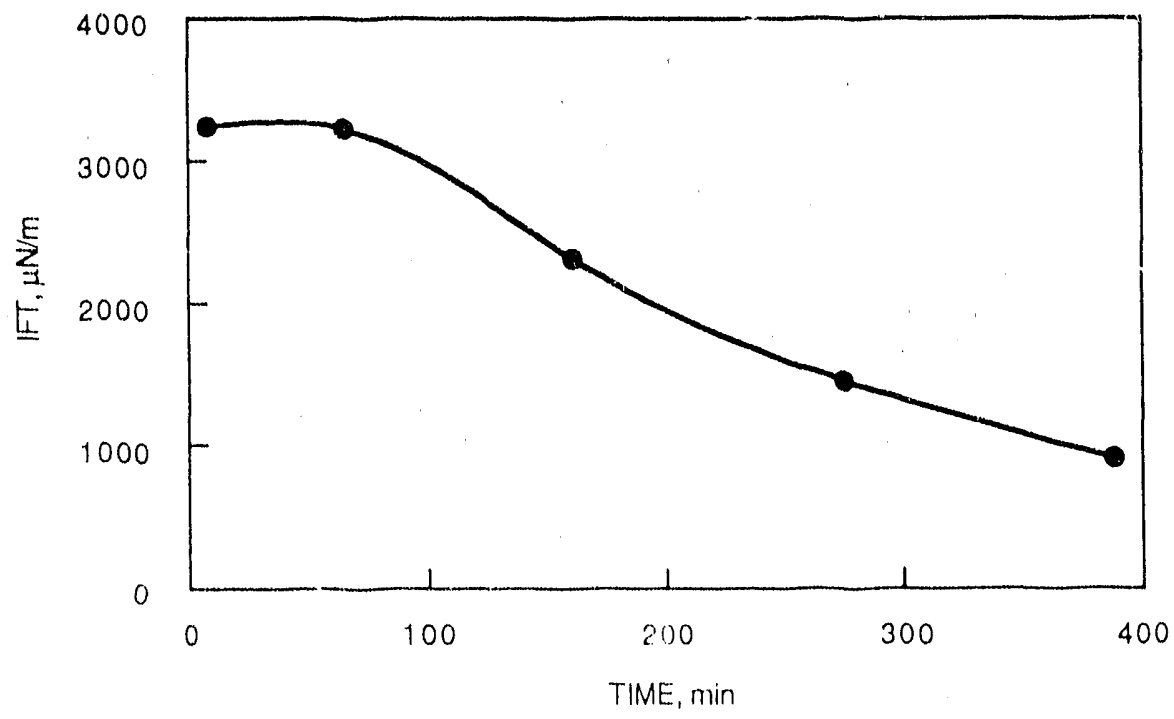

FIGURE 2. - Dynamic IFT of Delaware-Childers oil and 0.1\% Petrostep B-100 inionic surfactant, $52^{\circ} \mathrm{C}, \mathrm{pH} 6.3$.

Since $52^{\circ} \mathrm{C}$ is above the reservoir temperature, additional IFT measurements were performed at $30^{\circ} \mathrm{C}$, which is nearer the reservoir temperature. Dynamic (with time) IFT values at $30^{\circ} \mathrm{C}$ for DelawareChilders crude oil and several surfactant formulations that contain weak alkaline additives are shown in 
figures 3,4 , and 5 . The results show that equilibrium IFT values below $10 \mu \mathrm{N} / \mathrm{m}$ were achieved at some conditions, but that very low initial IFT values were not achieved. This contrasts with the IFT values previously measured at the higher temperature.

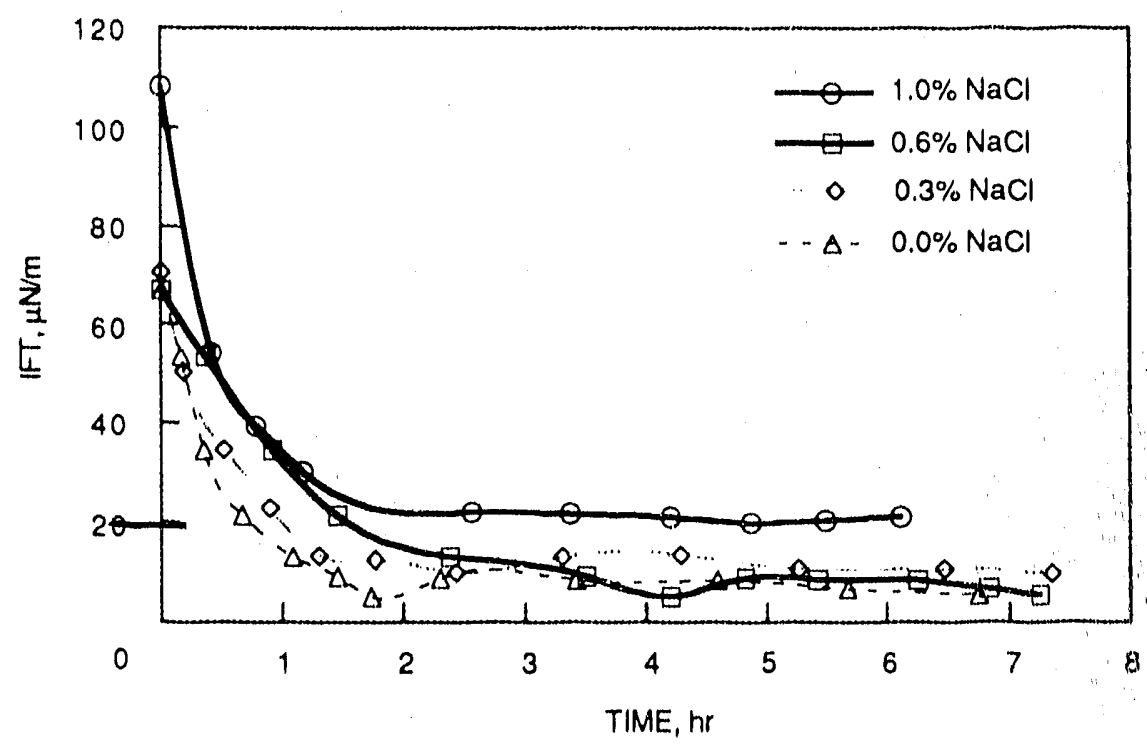

FIGURE 3. - Dynamic IFT of Delaware-Childers oil and $0.2 \%$ Petrostep B-100 anionic surfactant, $30^{\circ} \mathrm{C}, \mathrm{pH} 9.5$.

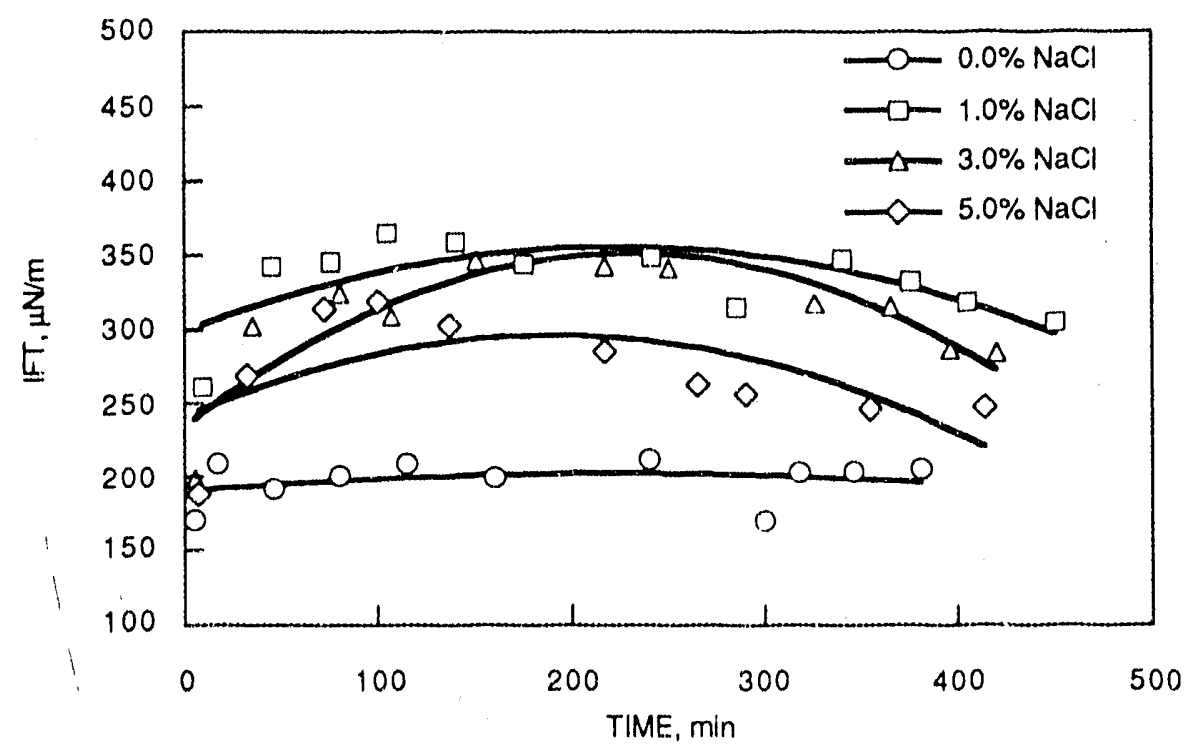

FIGURE 4. - Dynamic IFT of Delaware-Childers oil and 0.2\% Neodol 25-9 (ethoxylated alcohol) surfactant, $30^{\circ} \mathrm{C}, \mathrm{pH} 9.5$. 


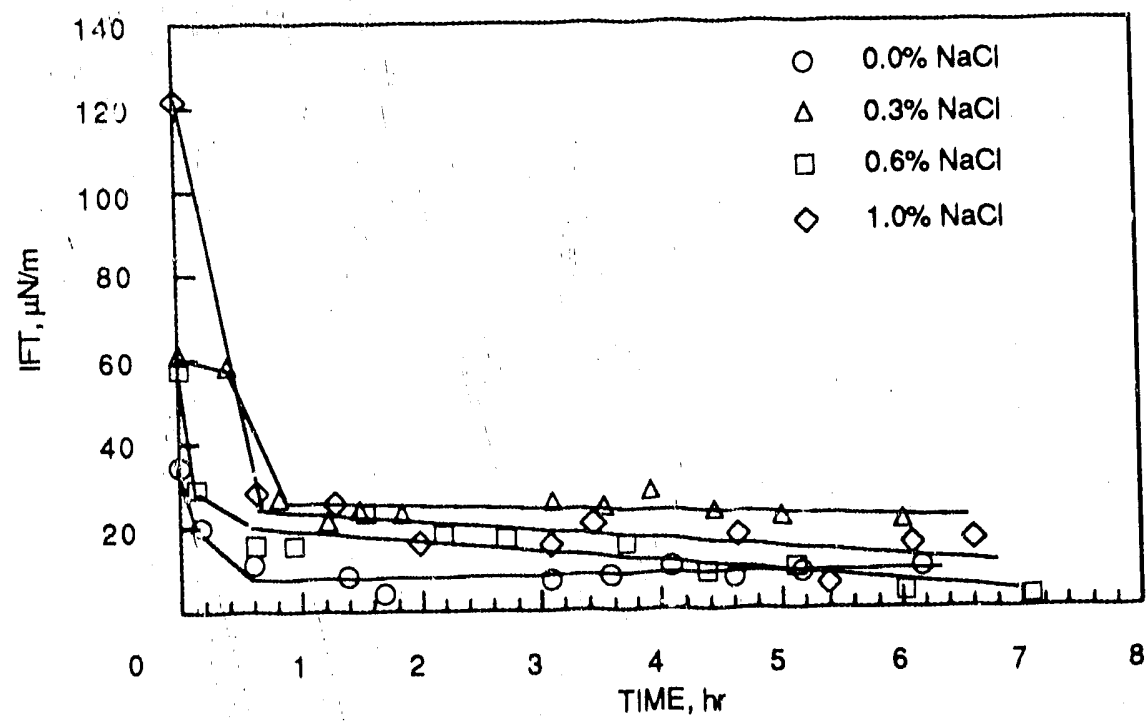

FIGURE 5. - Dynamic IFT of Delaware-Childers oil and $0.2 \%$ Petrostep B-100 anionic surfactant, $30^{\circ} \mathrm{C}, \mathrm{pH} 8.3$.

Since it was previously shown that the IFT value that results immediately after oil and surfactant solution come into contact is very important for mobilization of residual oil, ${ }^{16}$ the initiai values for IFT of selected surfactant systems are shown in figure 6 . The addition of an alkaline additive to a dilute solution of Petrostep B-100 anionic surfactant substantially reduces the initial IFT at $30^{\circ} \mathrm{C}$. The IFT of the surfactant solution without $\mathrm{pH}$ adjustment $(\mathrm{pH} 6.3)$ at $1.5 \% \mathrm{NaCl}$ concentration is nearly as low as the IFT of the alkaline/surfactant solution at $0 \% \mathrm{NaCl}$. However, the alkaline/surfactant solution (at $0 \% \mathrm{NaCl}$ ) has much less furbidity than the $\mathrm{pH} 6.3$ surfactant solution at $1.5 \% \mathrm{NaCl}$ concentration. It was shown that this turbidity can result in severe phase trapping in porous media. Therefore, one advantage of the alkaline solution is that low IFT was achieved at a condition where phase trapping is expected to be less of a problem.

A series of phase behavior tests were performed at $30^{\circ} \mathrm{C}$ with several surfactant and alkali mixtures. The conditions tested are shown in appendix $A$. The results of the phase behavior tests indicated that ultralow IFT values were obtained only with a mixture that contained Petrostep B-100 and $0.8 \%$ sodium bicarbonate. The dynamic IFT values of Delaware-Childers oil, Petrostep B-100 surfactant, and two different concentrations of sodiun bicarbonate are shown in figure 7. Neither system gives ultralow initial IFT; however, the lower sodium bicarbonate concentration gives substantially better dynamic behavior. The IFT is below $1 \mu \mathrm{N} / \mathrm{m}$ in 5 minutes, which is a short time period in the time-scale of a chemical flood 


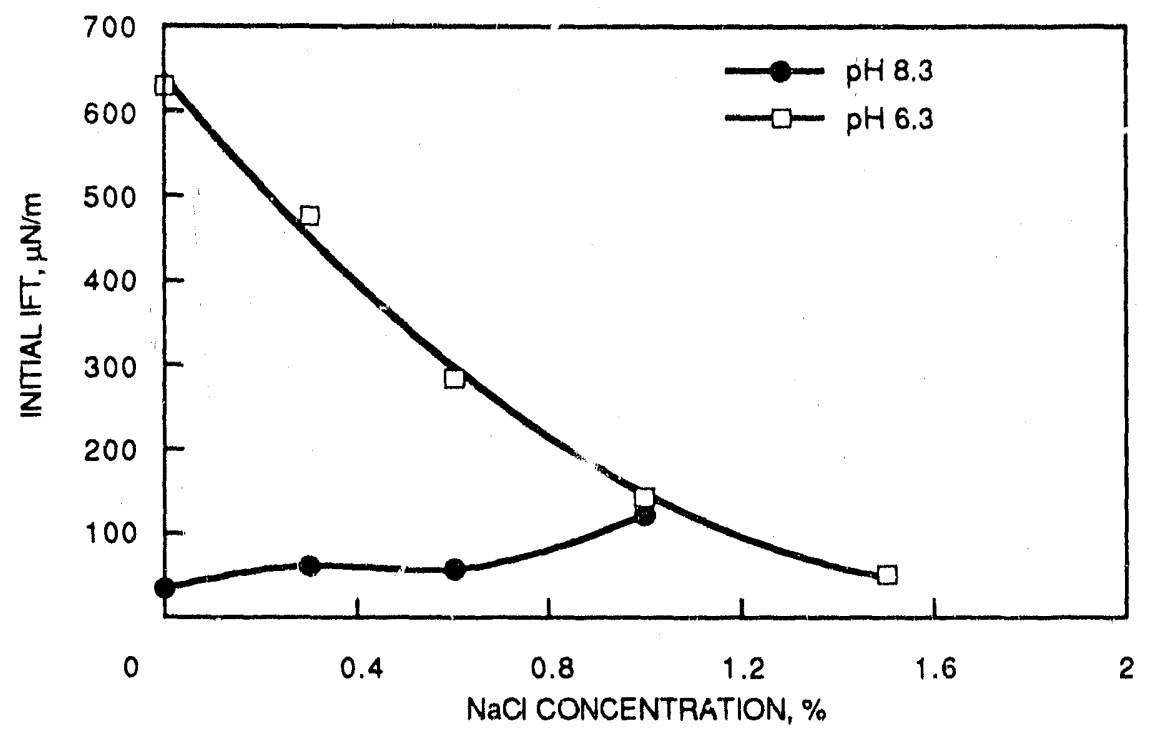

FIGURE 6. - Dynamic Initial IFT values measured with Delaware-Childers oil and $0.2 \%$ Petrostep B-100 anionic surfactant, $30^{\circ} \mathrm{C}, \mathrm{pH} 6.3$ and $\mathrm{pH} 8.3$.

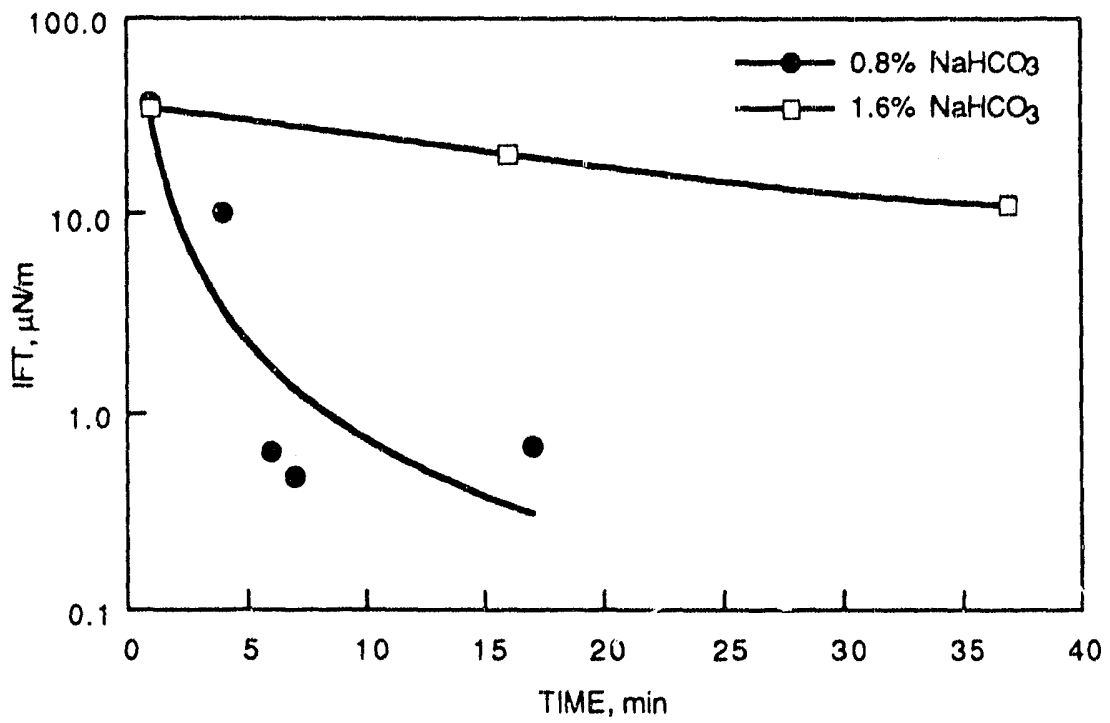

FIGURE 7. - Comparison of Dynamic IFT of Delaware-Childers oil and Petrostep B-100 anionic surfactant at two alkali concentrations, $30^{\circ} \mathrm{C}, \mathrm{pH} 8.3$. 
Polymer, for mobility control, is often included as part of a chemical injection formulation. This is one of several injection strategies that can be used. Comparison of figures 7 and 8 shows that addition of Pfizer Flocon $4800 \mathrm{CX}$ biopolymer s the alkali/surfactant solution has liftle effect on the dynamic IFT behaviur of Petrostep B-100 surfactant in $1.6 \%$ sodium bicarbonate solution. The effect is, however, 10 degrade the IFT behavior of the solution that contains $0.8 \%$ sodium bicarbonate. This indicates that the interactions of the several EOR chemicals must be taken into account when attempting to find the optimal injection strategy.

Results of oil recovery (coreflood) tests are simmarized in table 2, and the individual coreflood reports are presented in appendix $B$. One of the tests was conducted with Teapot Dome oil and will be discussed later. The other four tests were conducted at $30^{\circ} \mathrm{C}$ with Delaware-Childers oil. As previously discussed, some of the chemical systems used for these tests gave very low equilibrium IFT values, but not ultralow equilibrium IFT values. Two of the corefloods (DCNS-1 and DCNS-3) were conducted with native state cores that had very low initial oil saturations. No oil was recovered from these cores during the chemical floods.

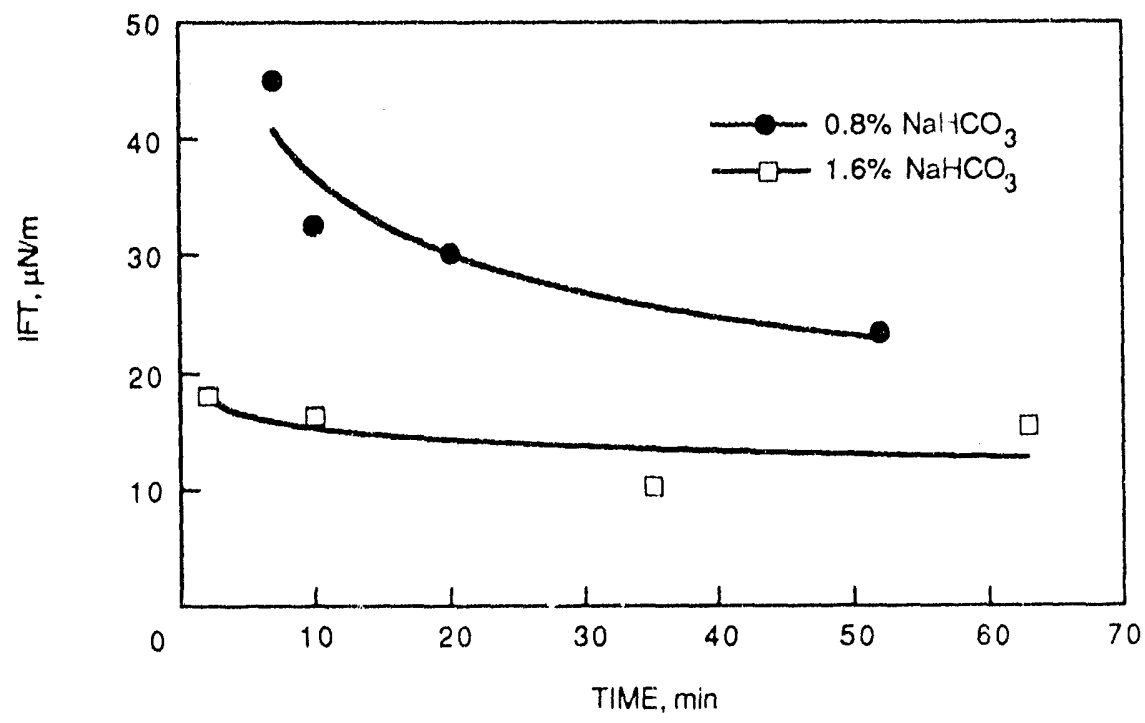

FIGURE 8. - Effect of polymer on the Dynamic IFT of Delaware-Childers oil and $0.2 \%$ Petrostep $B$ 100 , anionic surfactant, $30^{\circ} \mathrm{C}, \mathrm{pH} 8.3$. 
TABLE 2. - Corefloods conducted with surfactant formulations that contain alkaline additives.

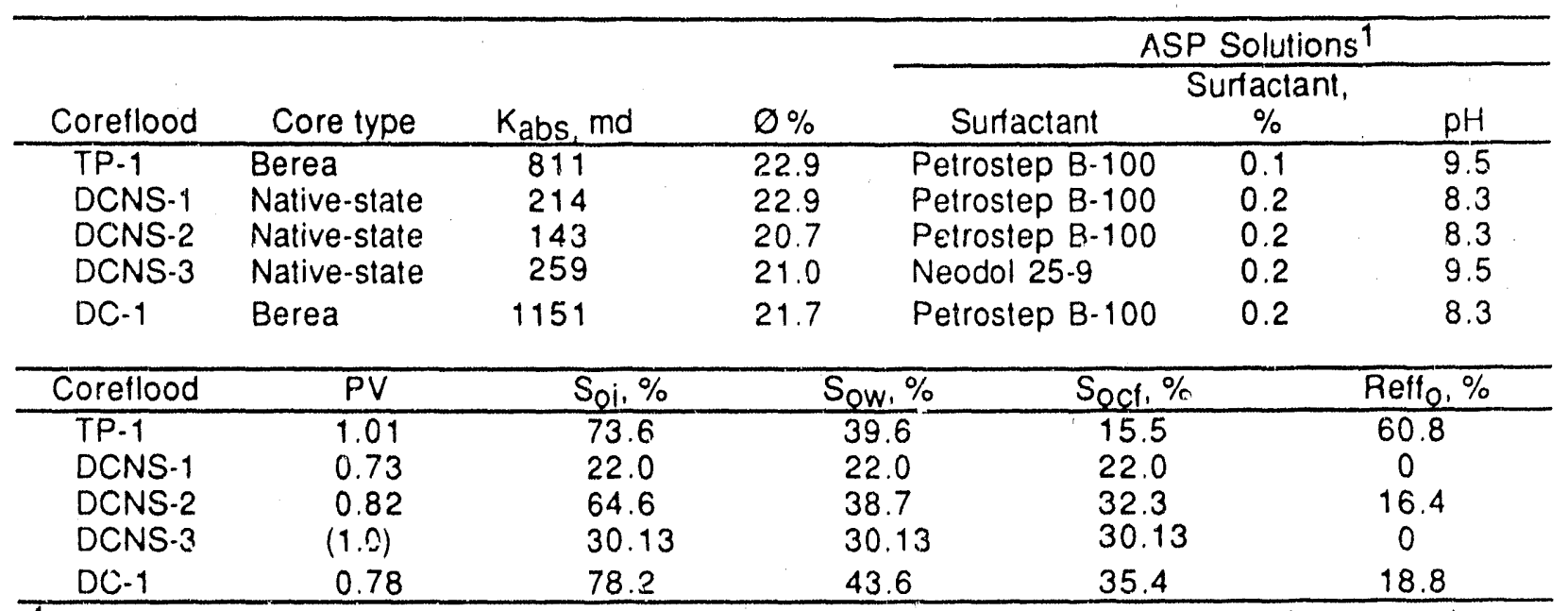

TAlkaline/surfactant/polymer (ASP) solutions contain weak alkali, low concentration surfactant, and Flocon $4800 \mathrm{CX}$ biopolymer.

Coreflood DCNS-2 was conducted in a native-state core that was first restored to initial oil saturation, and coreflood DC-1 was conducted with a Berea sandstone core. In both cases, the chemical flood was conducted after waterllooding the cores to residual oil saturation. The chinges in oil saturations during these chemical floods are shown in figure 9. The oil recovery results from the two core lests are remarkably close. Recovery from the restored native state core was $16.4 \%$, and recovery from Berea was $18.8 \%$.

The oil recoveries with Delaware-Childers oil were low and indicated that the surfactant formulations did not have low enough IFT values to mubilize significant residual oil. Work is continuing in an effort to find a surfactant formulation that will be more effective at reservoir temperature. It appears that low initial IFT may be more important for mobilization of oil than equilibrium values. A more encouraging result is shown in figure 10. The consumption of the alkaline additive by Delaware-Childers core was relatively low, despite the presence of substantial amounts of kaolinite.

\section{Teapot Dome (WY) Crude OII}

Crude oil from Teapot Dome (WY) oil field was also used for oil recovery tests. Teaput-Dome oil has essentially no acid content (i.e. acids that can be measured by titration witi potassium hydroxide) and represents an extreme case for testing the effects of alkaline additives. The oil has an API gravity of 34.1 and an acid number of $0.01 \mathrm{mg} \mathrm{KOH} / \mathrm{g}$ of oil. Results of dynamic IFT measurements are shown in figure 11. Addition of an alkaline additive to a dilute surfactant solution had a beneficial effect on the lowering of IFT. The effect on initial IFT is especially pronounced, with the additive lowering the initial IFT by three magnitudes. The initial IET with alkaline additive was ultra-low. 


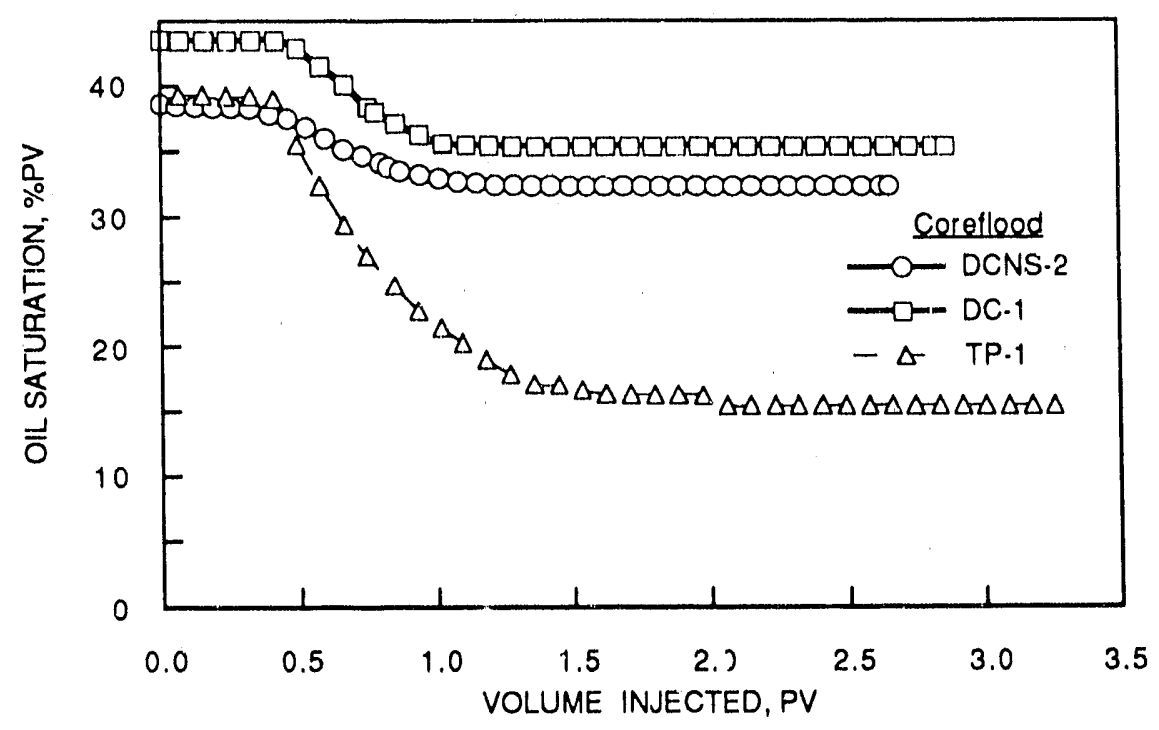

FIGURE 9. - Changes in oil saturations during chemical floods conducted with surfactant formulations that contain alkaline additives.

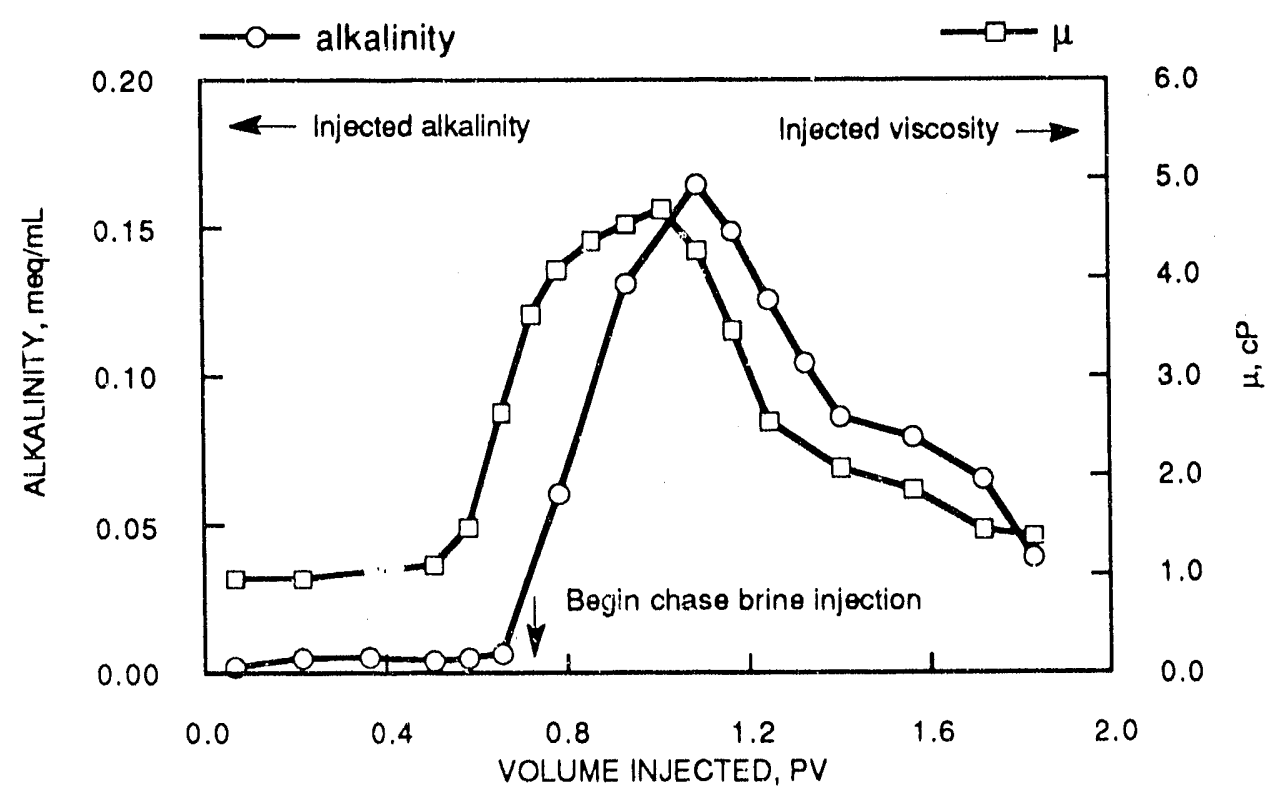

FIGURE 10. - Effluent analysis for chemical flood DCNS-1. 


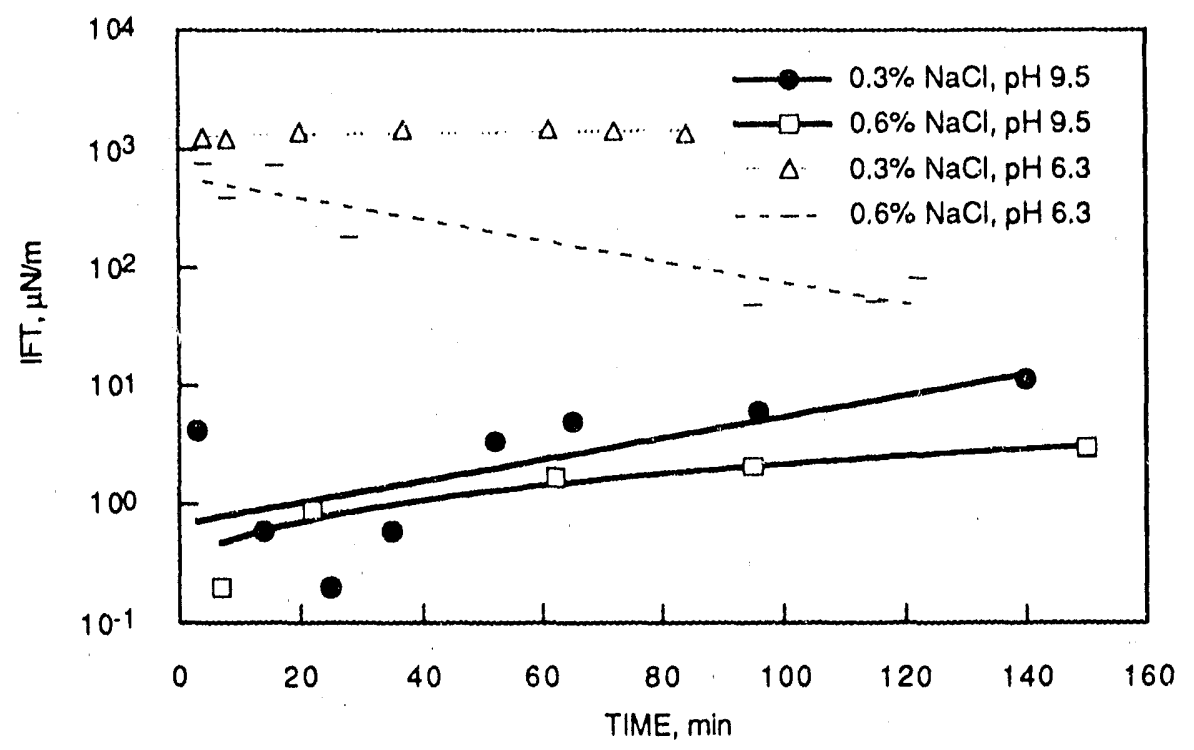

FIGURE 11. - Dynamic IFT of Teapot Dome oil and 0.1\% Petrostep B-100 anionic surfactant, $52^{\circ} \mathrm{C}, \mathrm{pH} 6.3$ and $\mathrm{pH} 9.5$.

The results of an oil recovery test with Teapot Dome oil are shown in table 2. The coreflood was conducted with Teapot Dome oil at $0.3 \% \mathrm{NaCl}$ concentration where the initial IFT was measured to be $0.6 \mu \mathrm{N} / \mathrm{m}$ and the equilibrium IFT was $9.6 \mu \mathrm{N} / \mathrm{m}$. Injection of the surfactant formulation resulted in recovery of $60.8 \%$ of the oil that remained in the core after a previous waterflood. The oil saturation (fig. 9) was lowered from $39.5 \%\left(S_{o w}\right)$ to $15.5 \%\left(S_{o c}\right)$ during chemical flood. The extremely gocd incremental oil recovery demonstrates the high recovery potential of properly designed dilute surfactant solutions that contain weakly alkaline additives.

The results of initial and equilibrium IFT measurements are shown in table 3. Examination of the table reveals that the initial IFT values for the Teapot Dome oil and Petrostep B-100 surfactant were almost 2 orders of magnitude lower than the best results achieved with the Delaware-Childers oil. This is, presumably, the explanation for the good oil recovery results with Teapot Dome oil and the poorer results previously discussed for Delaware-Childers oil.

The effluent analysis for the flood conducted with Teapot Dome oil is shown in figure 12. Surfactant adsorption was $0.129 \mathrm{meq} / \mathrm{kg}$, which is low. There was, however, an interesting separation of the surfactant and polymer in the effluent. The magnitude of this separation, over $0.5 \mathrm{PV}$, would be significant in a field situation. It may be possible to mitigate this effect with a different injection strategy. 
TABLE 3. - Dynamic interfacial tension of surfactant formulations that contain alkaline d te iv.

\begin{tabular}{ccccc}
\hline $\mathrm{pH}$ & $\begin{array}{c}\text { Temperature, } \\
{ }^{2} \mathrm{C}\end{array}$ & $\begin{array}{c}\mathrm{NaCl}, \\
\%\end{array}$ & $\begin{array}{c}\text { Initial IFT, } \\
\mu \mathrm{N} / \mathrm{m}\end{array}$ & $\begin{array}{c}\text { Equilibrium IFT, } \\
\mu \mathrm{N} / \mathrm{m}\end{array}$ \\
\hline Teapot Dome, $0.1 \%$ Petrostep B-100, carbonate & $\begin{array}{c}\% \\
\text { mixture }\end{array}$ & & \\
9.5 & & 0 & 5.4 & 21.1 \\
& 52 & 0.3 & 0.6 & 9.6 \\
& 0.6 & 0.9 & 5.4 \\
& 1.0 & 10.0 & 8.7 \\
\hline
\end{tabular}

\begin{tabular}{cc}
\hline Teapot Dome, $0.1 \%$ Neodol $25-9$, carbonate mixture \\
9.5 & 52 \\
&
\end{tabular}

$\begin{array}{ll}0 & 311.5 \\ 1 & 564.6 \\ 3 & 361.5 \\ 5 & 525.3 \\ 9 & 595.5\end{array}$

86.3

228.6

104.1

154.2

82.1

Delaware/Childers, $0.2 \%$ Petrostep $\mathrm{B}-100$, sodium bicarbonate

8.3

30

0
0.3
0.6

34.5

61.3

9.0

57.6

23.6

1.0

121.9

6.3

13.8

Delaware/Childers, $0.2 \%$ Petrostep E-100, carbonate mixture

9.5

30

0

0.3

0.6

1.0

67.

67.1

7.4

70.8

11.3

108.3

13.8

20.6

Delaware/Childers, $0.2 \%$ Neodol $25-9$, carbonate mixture

9.5

30

\section{0 \\ 1 \\ 3 \\ 5}

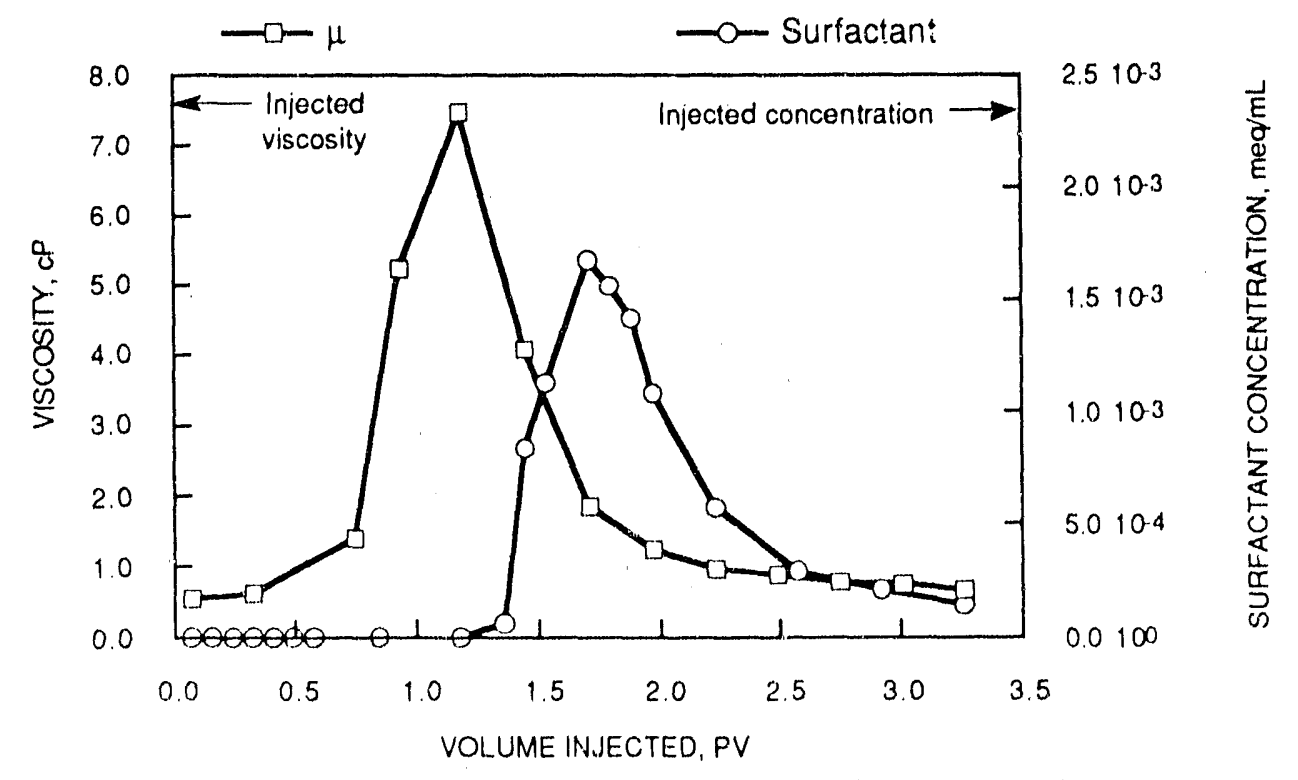

FIGURE 12. - Effluent analysis for chemical flood TP-1.
209.3

261.7

198.9

188.4

195.5

326.6

301.4

253.5 


\section{Hepler (KS) Crude OII}

Oil was obtained from the Tucker sand in Hepler (KS) oil field. Hepler field is the potential site of a test of surfactant flooding formulation that may contain alkaline additives. Favorable reservoir characteristics are low salinity and low divalent ion levels. However, low acid number is a reservoir characteristic that is not especially encouraging for the use of alkaline additives. The oil is $26.1^{\circ} \mathrm{API}$ gravity, and the acid number is less than $0.01 \mathrm{mg} \mathrm{KOH} / \mathrm{g}$ of oil.

Phase behavior tests were conducted with several surfactantalkali systems. The actual systems tested are given ir, appendix A. None of these systems exhibited the type of phase behavior that indicates ultralow IFT. The initial (after 1 to 2 minutes) IFT of the most promising system is shown in figure 13. The lowest initial IFT measured was $97 \mu \mathrm{N} / \mathrm{m}$, which was with a chemical system that contained $2.12 \% \mathrm{NaCl}$, a pit 9.5 carbonate mixture, and $0.2 \%$ Petrostep B-120, a low-molecular-weight anionic surfactant. The same figure shows the IFT values for $0.2 \%$ Petrostep B-120 without pH adjustment (pH 6.3) at three $\mathrm{NaCl}$ concentrations. Comparison reveals that the alkaline additive lowered the initial IFT only slightly. It was noted, however, that the repeatability of IFT measurements was much better for formulations that contained the alkaline additive.

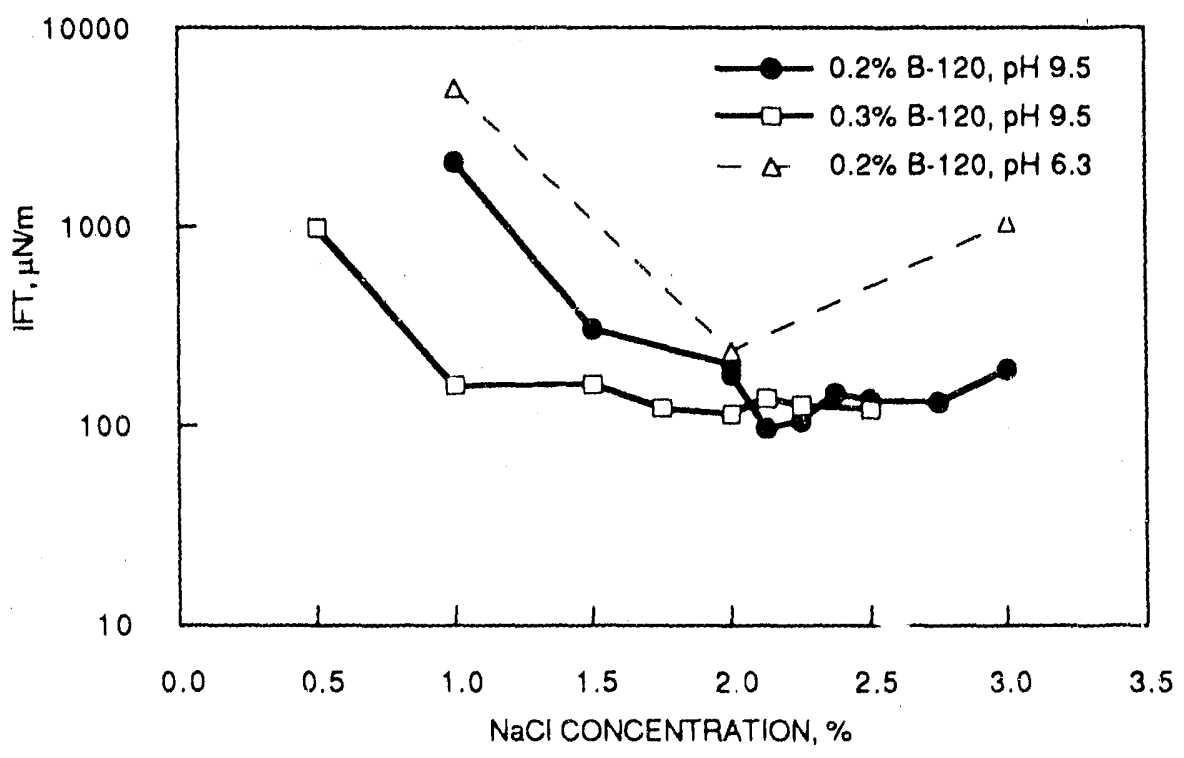

FIGURE 13. - Dynamic initial IFT values measured with Hepler oil and Petrostep B-120 anionic surfactant, $27^{\circ} \mathrm{C}, \mathrm{pH} 6.3$ and pH 9.5 . 


\section{Other Effects of Alkaline Additives}

In addition to the effect on lowering the IFT with some crude oils, alkalit, additives have other beneficial effects during surfactant floods. These effects should be considered when designing a flood. Calcium and magnesium lons present in reservoirs can precipitate the surfactants used in EOR applications. Alkalis are effective for reducing the levels of divalent ions in petroleum reservoirs. ${ }^{7,17}$ The effectiveness of the different alkalis for reducing divalent ion levels are: hydroxide < carbonate < silicate. For this purpose, the preferred injection strategy is probably to use an alkaline preflush to reduce divalent ion levels before injecting the formulation that contains surfactant.

Surfactant levels in the injected solution can also be reduced by adsorption onto reservoir rock. Alkali reduces the loss of surfactants by adsorption. Adsorption of anionic surfactants onto pure clay minerals is reduced as much as $93 \%$. Reductions of 7 to $49 \%$ were reported when reservoir sandstones are used. $3,5,18-19$

\section{When To Use Alkaline Additives}

The reservoir mineral and brine properties that are most important for determining the feasibility of alkaline flooding were previously identified. The criteria were identified after a detailed study of the alkaline field projects conducted since 1960. 15 Some of the data published in the chemical literature and the results of laboratory experiments were especially useful in correlation of mineralogy and the allowable $\mathrm{pH}$ level of the injected fluids. This is particularly important because the very high $\mathrm{pH}$ alkalis are completely consumed by some of the minerals in petroleum reservoirs. A summary of the screening criteria follows.

\section{Carbon Dioxide}

The $\mathrm{CO}_{2}$ content of petroleum reservoirs is reported only infrequently. Yet, it is one of the most important parameters for determining if a reservoir is a candidate for alkaline flooding. Alkaline flooding should usually not be considered in reservoirs of high $\mathrm{CO}_{2}$ content: mole fraction of $\mathrm{CO}_{2}$ (in produced gas) $>0.01$ or $\mathrm{pH}<6.5 .15,20$

\section{Mineralogy}

\section{axperm}

The presence of gypsum (anhydrite) is a deterrent to any type of alkaline (or surfactant) flooding. It has been shown that $1 \%$ gypsum in a reservoir can consume $10 \mathrm{PV}$ of a $1 \%$ solution of $\mathrm{NaHCO}_{3}$. Alkaline flooding should be rejected for any reservoir with greater than $0.1 \%$ gypsum. This amount of gypsum can be inferred from 1,000 ppm sulfate ion in the brine. ${ }^{15}$ 


\section{Kaollinite}

The presence of kaolinite is a serious deterrent to flooding with the higher $\mathrm{pH}$ alkalis. ${ }^{21}$ Only fow $\mathrm{pH}$ (about 8.2 - 10) alkalis should be considered for use in reservoirs that contain appreciable amounts of kaolinite.

\section{Montmorlllonite (smectlte)}

Montmorillonite, which is less reactive with alkalis, is detrinental to alkaline flooding processes because of its high surface area and very high cation exchange capacity. High CEC values are associated with high montmorillonite content. If divalent ions occupy the exchange sites, much of the injected alkali can be consumed by adverse precipitation reactions. The screening criterion for ion exchange capacity is $5 \mathrm{meq} / \mathrm{kg}$. This corresponds roughly with the presence of $1 \%$ montmorillonite and $0.4 \mathrm{wt} \%$ of divalent ions in the brine. 15,22

\section{Limestone}

The high $\mathrm{pH}$ alkalis are reactive with limestone and should be avoided in dolomitic reservoirs. Low $\left(\mathrm{NaHCO}_{3}\right)$ and moderate $\left(\mathrm{Na}_{2} \mathrm{CO}_{3}\right) \mathrm{pH}$ carbnnates have been shown to be compatible with dolomitic cores. $3,9,23$

\section{Other Parameters}

Other parameters such as temperature, permeability, salinity, and oil viscosity have the familiar limits for chemical flooding, whose values depend on the specific limitations of the surfactant and polymer. 15

\section{SUMMARY AND CONCLUSIONS}

The motivation for this work was to determine if the addition of alkaline additives will allow the design of surfactant formulations that are effective for the recovery of crude oils with a wide range of properties, while at the same time maintaining the surfactant concentration at a much lower level than has previously been used for micellar flooding. Specifically, the focus of the work is on light, midcontinent crudes that typically have very low acid contents. These oils are typical of much of the midcontinent resource.

The positive effect of alkaline additives on the phase behavior of surfactant formulations and acidic crude oils is well known. The extension to non-acidic and slightly acidic oils is not deductively obvious. Three crude oils, a variety of commercial surfactants, and several alkaline additives were tested during this project. The oils had acid numbers that ranged from 0.13 , which is quite low, down to less than $0.01 \mathrm{mg}$ $\mathrm{KOH} / \mathrm{g}$ of oil. 
Additives were found to be very effective with Delaware-Childers (OK) oll at ele' ated temperuture, but much less effective at reservoir temperature. Alkaline additives were very effective with Teapot-Dome (WY) oil. Surfactant/alkal' systems produced ultra-low IFT values and recovered $60 \%$ of the residual oil that remained after waterloouing. The effect of alkaline additives on the Hepler (KS) oil was minimal.

The overall conclusion is that alkaline additives do have merit for use in surfactant flooding of low acid crude oils; however, as shown above, each oil behaves differeriliy, and the effect of alkaline additives must be determined at reservoir conditions for each oll.

\section{REFERENCES}

1. Nationa! Petroleum Council: Enhanced Oil Recovery. Washington D.C., 1984.

2. French, T. R., D. A. Peru, and S. D. Thornton. Low pH Alkaline Chemical Formulations, Dept. of Energy Report No. NIPER-375, October 1988.

3. French, T. R. Design and Optimization of Phosphate-Contalling Alkaline Flooding Formulations. Dept. of Energy Report No. NIPER-446, September 1989.

4. Clark, S. R., I. M. Pitts, and S. M. Smith. Design and Application of an Alkaline-Surfactant-Polymer Recovery System to West Kiehl Field. Presented at Soc. Pet. Eng. Rocky Mountain Regional Meeting, May 1988, SPE paper 17538.

5. Krumrine, P. H., J. S. Falcone, Jr., and T. C. Campbell. Surfactant Flooding 1: The Effect of Alkaline Additives on IFT, Surfactant Adsorption, and Recovery Efficiency. Soc. Pet. Eng. J., v. 22, No. 4, August 1982.

6. Burk, J. H. Comparison of Sodium Carbonate, Sodium Hydroxide, and Sodium Orthosilicate for EOR, SPE Reservoir Eng., v. 2, No. 1, February 1987, pp. 9-16.

7. French, T. R. and T. E. Burchfield. Design and Optimization of Alkaline Flooding Formulations. Pres, at the Seventh Joint SPE/DOE Symposium on Enhanced Oil Recovery. Tulsa, OK. April 1990. SPE/DOE paper 20238.

8. Martin, F. D., J. C. Oxley, and H. Lim. Enhanced Recovery of a "J" Sand Crude Oil With a Combination of Surfactant and Alkaline Chemicals. Fres. at the 60th Ann. Tech. Conf. and Exhib. of the Society of Petroleum Engineers. Las Vegas, NV. September 1985. SPE paper 14293. 
9. Olsen, D. K., M. D. Hicks, and B. G. Hurd. Design of a Novel Flooding System for an Oil-Wet Central Texas Carbonate Fieservoir. Pres. at the Seventh Joint SPE/DOE Symposium on Enhanced Oil Recovery. Tulsa, OK, April 1990, SPE/DOE paper 20224.

10. Peru, D. A. Aqueous Flooding Methods for Tertiary Oil Recovery. U.S. Patent 4,817,715, ApıI 1989.

11. Nelson, R. C., J. B. Lawson, D. R. Thigpen, and G. L. Stegerneler. Cosurfactant-Enhanced Alkaline Flooding. Pres. at the Fourth Joint SPE/DOE Symposium on Enhanced Oil Recovery, Tulsa, OK, Apr. 16-18, 1984. SPE/DOE paper 12672.

12. Wasan, D. T. Enhanced Oil Recovery Through In Situ Generated Surfactants Augmented by Chemical Injection. Illinois Institute of Technology Annual Report, 1989.

13. Rosen, M. J. and H. A. Goldsmith. Systematic Analysis of Surface Active Agents. WileyInterscience, New York, 1972, pp. 423-424.

14. Hofman, Y. L. and H. P. Angstadt. Analysis of Enhanced Oll Recovery Formulations. Chromatographia, v. 24, 1987, pp. 666-679.

15. Lorenz, P. B. and D. A Peru. Guidelines Help Select Reservoirs for NaHCO3 EOR, Oil \& Gas J., v. 87, No. 37, Sept. 11, 1989, pp. 53-57.

16. Taylor, Kevin C. and Blaine F. Hawkins. Dynamic Interfacial Tension in Surfactant Enhanced Alkaline Flooding. Pres. at the 40th Ann. Tech. Meeting of the Petroleum Soc. of CIM. Banff, Canada, May 1989. Paper 89-40-44.

17. Labrid, J. and B. Bazin. Alkaline Preflush in a Low-Permieability Clayey Sandstone. J. Pet. Sci. Eng., v. 3, 1989, pp. 111-120.

18. Peru, D. A. and P. B. L.orenz. Surfactant-Enhanced Low pH Alkaline Flooding. SPE paper 17117.

19. Hurd, B. G. Adsorption and Transport of Chemical Species in Laboratory Surfactant Waterflooding Experiments. Pres, at Soc. Pet. Eng. Improved Oil Recovery Symposium, Tulsa, CK, Mar. 22-24, 1976, SPE paper 5818.

20. Collins, A. G. Geochemistry of Oiffield Waters, Elsevier Scientific Publishing Co., 1975. 
21. Thornton, S. D. Reaction of Sodlum Hydroxide with Silicate Minerals, Depl. of Energy Report No. NIPER-129, April 1986, NTIS Order No. BE86000275.

22. Smith, F. W. lon-Exchange Conditioning of Sanc'stones for Chemical Flooding. J. Pet. Tech., $v$. 30, June 1978, pp. 959-968.

23. Cheng, K. H. Chemical Consumption During Alkaline Flooding: A Comparative Evaluation. Pres, at the Fifth Joint SPE/DOE Symposium on Enhanced Oil Recovery, Tulsa, OK, Apr. 20-23, 1986, SPE/DOE paper 14944. 
APPENDIX A

Phase Behavlor tests, $30^{\circ} \mathrm{C}$

\begin{tabular}{|c|c|c|c|}
\hline Oil & Surtactant & $\mathrm{NaCl}, \%$ & $\mathrm{pH}$ \\
\hline Delaware/Childers & $0.1 \%$ Neodol 25-9 & 1.0 & 9.5 \\
\hline Delaware/Childers & $.1 \%$ Neodol $25-9$ & 3.0 & 9.5 \\
\hline Delaware/Childers & $.1 \%$ Neodol $25-9$ & 6.0 & 9.5 \\
\hline Delaware/Childers & $.1 \%$ Neodol $25-9$ & 10.0 & 9.5 \\
\hline Delaware/Childers & $.2 \%$ Neodol 25.9 & 1.0 & 9.5 \\
\hline Delaware/Childers & $2 \%$ Neodol $25-9$ & 3.0 & 9.5 \\
\hline Delaware/Childers & $.2 \%$ Neodol 25-9 & 6.0 & 9.5 \\
\hline Delaware/Childers & $.2 \%$ Neodol 25.9 & 10.0 & 9.5 \\
\hline Delaware/Childers & $.4 \%$ Neodol $25-9$ & 1.0 & 9.5 \\
\hline Delaware/Childers & $.4 \%$ Neodol $25-9$ & 3.0 & 9.5 \\
\hline Delaware/Childers & $.4 \%$ Neodol 25.9 & 6.0 & 9.5 \\
\hline Delaware/Childers & $.4 \%$ Neodol $25-9$ & 10.0 & 9.5 \\
\hline Delaware/Childers & $.8 \%$ Neodol $25-9$ & 1.0 & 9.5 \\
\hline Delaware/Childers & $.8 \%$ Neodol $25-9$ & 3.0 & 9.5 \\
\hline Delaware/Childers & $.8 \%$ Neodol $25-9$ & 6.0 & 9.5 \\
\hline Delaware/Childers & $.8 \%$ Neodol 25.9 & 10.0 & 9.5 \\
\hline Delaware/Childers & $.1 \%$ Neodol $25-9$ & 1.0 & 10.0 \\
\hline Delaware/Childers & $.1 \%$ Neodol $25-9$ & 3.0 & 10.0 \\
\hline Delaware/Childers & $.1 \%$ Neodol 25.9 & 6.0 & 10.0 \\
\hline Delaware/Childers & $.1 \%$ Neodol $25-9$ & 0.0 & 10.0 \\
\hline Delaware/Childers & $.2 \%$ Neodiol $25-9$ & 1.0 & 10.0 \\
\hline Delaware/Childers & $.2 \%$ Neodol $25-9$ & 3.0 & 10.0 \\
\hline Delaware/Childers & $.2 \%$ Neodol $25-9$ & 6.0 & 10.0 \\
\hline Delaware/Childers & $.2 \%$ Neodol $25-9$ & 10.0 & 10.0 \\
\hline Delaware/Childers & $.4 \%$ Neodol 25.9 & 1.0 & 10.0 \\
\hline Delaware/Childers & $.4 \%$ Neodol $25-9$ & 3.0 & 10.0 \\
\hline Delaware/Childers & $.4 \%$ Neodol 25-9 & 6.0 & 10.0 \\
\hline Delaware/Childers & $.4 \%$ Neodol $25-9$ & 10.0 & 10.0 \\
\hline Delaware/Childers & $.8 \%$ Neodol $25-9$ & 1.0 & 10.0 \\
\hline Delaware/Childers & $.8 \%$ Neodol 25.9 & 3.0 & 10.0 \\
\hline
\end{tabular}




\begin{tabular}{|c|c|c|c|}
\hline Oil & Surfactant & $\mathrm{NaCl}, \%$ & $\mathrm{pH}$ \\
\hline Delaware/Childers & $.8 \%$ Neodol $25-9$ & 6.0 & 10.0 \\
\hline Delaware/Childers & $.8 \%$ Neodol $25-9$ & 10.0 & 10.0 \\
\hline Delaware/Childers & $.1 \%$ Neodol $25-9$ & 1.0 & 10.5 \\
\hline Delaware/Childers & $.1 \%$ Neodol 25-9 & 3.0 & 10.5 \\
\hline Delaware/Childers & $.1 \%$ Neodol $25-9$ & 6.0 & 10.5 \\
\hline Delaware/Childers & $.1 \%$ Neodol $25-9$ & 10.0 & 10.5 \\
\hline Delaware/Childers & $.2 \%$ Neodol $25-9$ & 1.0 & 10.5 \\
\hline Delaware/Childers & $.2 \%$ Neodol $25-9$ & 3.0 & 10.5 \\
\hline Delaware/Childers & $.2 \%$ Neodol $25-9$ & 6.0 & 10.5 \\
\hline Delaware/Childers & $.2 \%$ Neodol $25-9$ & 10.0 & 10.5 \\
\hline Delaware/Childers & $.4 \%$ Neodol $25-9$ & 1.0 & 10.5 \\
\hline Delaware/Childers & $.4 \%$ Neodol 25-9 & 3.0 & 10.5 \\
\hline Delaware/Childers & $.4 \%$ Nevidol 25-9 & 6.0 & 10.5 \\
\hline Delaware/Childers & $.4 \%$ Neodol 25-9 & 10.0 & 10.5 \\
\hline Delaware.'Shilders & $.8 \%$ Neodol $25 \% 9$ & 1.0 & 10.5 \\
\hline Delaware/Childers & $.8 \%$ Neodol $25-9$ & 3.0 & 10.5 \\
\hline Delaware/Childers & $.8 \%$ Neodol $25-9$ & 6.0 & 10.5 \\
\hline Delaware/Childers & $.8 \%$ Neodol $25-9$ & 10.0 & 10.5 \\
\hline Delaware/Childers & $.1 \%$ Petrostep B-100 & 0.3 & 9.5 \\
\hline Delaware/Childers & $.1 \%$ Petrostep B-100 & 0.6 & 9.5 \\
\hline Delaware/Childers & $.1 \%$ Petrostep B-100 & 1.0 & 9.5 \\
\hline Delaware/Childers & $.1 \%$ Petrostep B-100 & 3.0 & 9.5 \\
\hline Delaware/Childers & $.2 \%$ Petrostep B-100 & 0.3 & 9.5 \\
\hline Delaware/Childers & $.2 \%$ Petrostep B-100 & 0.6 & 9.5 \\
\hline Delaware/Childers & $.2 \%$ Petrostep B.100 & 1.0 & 9.5 \\
\hline Delaware/Childers & $2 \%$ Petrostep B-100 & 3.0 & 9.5 \\
\hline Delaware/Childers & $.4 \%$ Petrostep B-100 & 0.3 & 9.5 \\
\hline Delaware/Childers & $.4 \%$ Petrostep B-100 & 0.6 & 9.5 \\
\hline Delaware/Childers & $.4 \%$ Petrostep B-100 & 1.0 & 9.5 \\
\hline Delaware/Childers & $.4 \%$ Petrostep B.100 & 3.0 & 9.5 \\
\hline Delaware/Childers & $.8 \%$ Petrostep B-100 & 0.3 & 9.5 \\
\hline Delaware/Childers & $.8 \%$ Petrostep B.100 & 0.6 & 9.5 \\
\hline Delaware/Childers & $.8 \%$ Petrostep B-100 & 1.0 & 9.5 \\
\hline Delaware/Childers & $.8 \%$ Petrostep B-100 & 3.0 & 9.5 \\
\hline
\end{tabular}




\begin{tabular}{|c|c|c|c|}
\hline Oil & Surfactant & $\mathrm{NaCl}, \%$ & $\mathrm{pH}$ \\
\hline Delaware/Childers & $.1 \%$ Petrostep B-100 & 0.3 & 10.0 \\
\hline Delaware/Childers & $.1 \%$ Petrostep B-100 & 0.6 & 10.0 \\
\hline Delaware/Childers & $.1 \%$ Petrostep B-100 & 1.0 & 10.0 \\
\hline Delaware/Childers & $.1 \%$ Petrostep B-100 & 3.0 & 10.0 \\
\hline Delaware/Childers & $.2 \%$ Petrostep B-100 & 0.3 & 10.0 \\
\hline Delaware/Childers & $.2 \%$ Petrostep B-100 & 0.6 & 10.0 \\
\hline Delaware/Childers & $.2 \%$ Petrostep B-100 & 1.0 & 10.0 \\
\hline Delaware/Childers & $.2 \%$ Petrostep B-100 & 3.0 & 10.0 \\
\hline Delaware/Childers & $.4 \%$ Petrostep B-100 & 0.3 & 10.0 \\
\hline Delaware/Childers & $.4 \%$ Petrostep B-100 & 0.6 & 10.0 \\
\hline Delaware/Criiiders & $.4 \%$ Petrostep B-100 & 1.0 & 10.0 \\
\hline Delaware/Childers & $.4 \%$ Petrostep B-100 & 3.0 & 10.0 \\
\hline Delaware/Childers & $.8 \%$ Petrostep B-100 & 0.3 & 10.0 \\
\hline Delaware/Childers & $.8 \%$ Petrostep B-100 & 0.6 & 10.0 \\
\hline Delaware/Childers & $.8 \%$ Petrostep B-100 & 1.0 & 10.0 \\
\hline Delaware/Childers & $.8 \%$ Petrostep B-100 & 3.0 & 10.0 \\
\hline Delaware/Childers & $.1 \%$ Petrostep B-100 & 0.3 & 10.5 \\
\hline Deiaware/Childers & $.1 \%$ Petrostep B-100 & 0.6 & 10.5 \\
\hline Delaware/Childers & $.1 \%$ Petiostep B-100 & 1.0 & 10.5 \\
\hline Delaware/Childers & $.1 \%$ Petrostep B-100 & 3.0 & 10.5 \\
\hline Delaware/Childers & $.2 \%$ Petrostep B-100 & 0.3 & 10.5 \\
\hline Delaware/Childers & $.2 \%$ Petrostep B-100 & 0.6 & 10.5 \\
\hline Delaware/Childers & $.2 \%$ Petrostep B-100 & 1.0 & 10.5 \\
\hline Delaware/Childers & $.2 \%$ Petrostep B-100 & 3.0 & 10.5 \\
\hline Delaware/Childers & $.4 \%$ Petrostep B-100 & 0.3 & 10.5 \\
\hline Delaware/Childers & $4 \%$ Petrostep B-100 & 0.6 & 10.5 \\
\hline Delaware/Childers & $.4 \%$ Petrostep B-100 & 1.0 & 10.5 \\
\hline Delaware/Childers & $.4 \%$ Petrostep B-100 & 3.0 & 10.5 \\
\hline Delaware/Childers & $.8 \%$ Petrostep B-100 & 0.3 & 10.5 \\
\hline Delaware/Childers & $.8 \%$ Petrostep B-100 & 0.6 & 10.5 \\
\hline Delaware/Childers & $.8 \%$ Petrostep B-100 & 1.0 & 10.5 \\
\hline Delaware/Childers & $.8 \%$ Petrostep B-100 & 3.0 & 10.5 \\
\hline Delaware/Childers & $.1 \%$ Petrostep B-100 & 0.3 & 8.3 \\
\hline Delaware/Childers & $.1 \%$ Petrostep B-100 & 0.6 & 8.3 \\
\hline
\end{tabular}




\begin{tabular}{|c|c|c|c|}
\hline Oil & Surfactant & $\mathrm{NaCl}, \%$ & $\mathrm{pH}$ \\
\hline Delaware/Childers & $.1 \%$ Petrostep B-100 & 1.0 & 8.3 \\
\hline Delaware/Childers & $.1 \%$ Petrostep B-100 & 3.0 & 8.3 \\
\hline Delaware/Childers & $.2 \%$ Petrostep B-100 & 0.3 & 8.3 \\
\hline Delaware/Childers & $.2 \%$ Petrostep B-100 & 0.6 & 8.3 \\
\hline Delaware/Childers & $.2 \%$ Petrostep B-100 & 1.0 & 8.3 \\
\hline Delaware/Childers & $.2 \%$ Petrostep B-100 & 3.0 & 8.3 \\
\hline Delaware/Childers & $.4 \%$ Petrostep B-100 & 0.3 & 8.3 \\
\hline Delaware/Childirs & $.4 \%$ Petrostep B-100 & 0.6 & 8.3 \\
\hline Delaware/Childers & $.4 \%$ Petrostep B-100 & 1.0 & 8.3 \\
\hline Delaware/Childers & $.4 \%$ Petrostep B-100 & 3.0 & 8.3 \\
\hline Delaware/Childers & $.8 \%$ Petrostep B-100 & 0.3 & 8.3 \\
\hline Delaware/Childers & $.8 \%$ Petrostep B-100 & 0.6 & 8.3 \\
\hline Delaware/Childers & $.8 \%$ Petrostep B-100 & 1.0 & 8.3 \\
\hline Delaware/Childers & $.8 \%$ Petrostep B-100 & 3.0 & 8.3 \\
\hline Teapot Dome & $.1 \%$ Petrostep B-100 & 0.0 & 8.3 and 9.5 \\
\hline Teapot Dome & $.1 \%$ Petrostep B-100 & 0.15 & 8.3 and 9.5 \\
\hline Teapot Dome & $.1 \%$ Petrostep B-100 & 0.30 & 8.3 and 9.5 \\
\hline Teapot Dome & $.1 \%$ Petrostep B-100 & 0.60 & 8.3 and 9.5 \\
\hline Teapot Dome & $.1 \%$ Petrostep B-100 & 1.0 & c.3 and 9.5 \\
\hline Teapot Dome & $.1 \%$ Petrostep B-100 & 1.5 & 8.3 and 9.5 \\
\hline Teapot Dome & $.1 \%$ Neodol $2.5-9$ & 0.0 & 8.3 and 9.5 \\
\hline Teapot Dome & $.1 \%$ Neodol $25-9$ & 1.0 & 8.3 and 9.5 \\
\hline Teapot Dome & $.1 \%$ Neodol $25-9$ & 2.0 & 8.3 and 9.5 \\
\hline Teapot Dome & $.1 \%$ Neodo! $25-9$ & 3.0 & 8.3 and 9.5 \\
\hline Teapot Dome & $.1 \%$ Neodol $25-9$ & 6.0 & 8.3 and 9.5 \\
\hline Teapot Dome & $.1 \%$ Neodol $25-9$ & 10.0 & 8.3 and 9.5 \\
\hline Hepler & $.1 \%$ GAF T-33 & 3.0 & unadjusted and $\mathrm{pH} 9.5$ \\
\hline Hepler & $.1 \%$ GAF T-33 & 5.0 & unadjusted and $\mathrm{pH} 9.5$ \\
\hline Hepler & $.1 \%$ GAF T-33 & 7.0 & unadjusted and $\mathrm{pH} 9.5$ \\
\hline Hepler & $.1 \%$ GAF T -33 & 9.0 & unadjusted and $\mathrm{pH} 9.5$ \\
\hline Hepler & $.1 \%$ GAF CA-720 & 3.0 & unadjusted and $\mathrm{pH} 9.5$ \\
\hline Hepler & $.1 \%$ GAF CA-720 & 5.0 & unadjusted and $\mathrm{pH} 9.5$ \\
\hline Hepler & $.1 \%$ GAF CA-720 & 7.0 & unadjusted and $\mathrm{pH} 9.5$ \\
\hline Hepler & $.1 \%$ GAF CA-720 & 9.0 & unadjusted and $\mathrm{pH} 9.5$ \\
\hline
\end{tabular}




\begin{tabular}{|c|c|c|c|}
\hline Oil & Surfactant & $\mathrm{NaCl} \%$ & $\mathrm{pH}$ \\
\hline Hepler & $.1 \%$ GAF C 0.730 & 3.0 & unadjusted and $\mathrm{pH} 9.5$ \\
\hline Hepler & $.1 \%$ GAF CO -730 & 5.0 & unadjusted and $\mathrm{pH} 9.5$ \\
\hline Hepler & $.1 \%$ GAF CO -730 & 7.0 & unadjusted and $\mathrm{pH} 9.5$ \\
\hline Hepler & $.1 \%$ GAF CO -730 & 9.0 & unadjusted and $\mathrm{pH} 9.5$ \\
\hline Hepler & $.1 \%$ GAF CO -850 & 3.0 & unadjusted and $\mathrm{pH} 9.5$ \\
\hline Hepler & $.1 \%$ GAF CO -850 & 5.0 & unadjusted and $\mathrm{pH} 9.5$ \\
\hline Hepler & $.1 \%$ GAF CO -850 & 7.0 & unadjusted and $\mathrm{pH} 9.5$ \\
\hline Hepler & $.1 \%$ GAF CO -850 & 9.0 & unadjusted and $\mathrm{pH} 9.5$ \\
\hline Hepler & $.1 \%$ Petrostep B-120 & 2.0 & 9.5 \\
\hline Hepler & $.1 \%$ Petrostep B-120 & 2.12 & 9.5 \\
\hline Hepler & $.1 \%$ Petrostep B-120 & 2.25 & 9.5 \\
\hline Hepler & $.1 \%$ Petrosiep B-120 & 2.38 & 8.5 \\
\hline Hepler & $.1 \%$ Petrostep B-120 & 2.50 & 9.5 \\
\hline Hepler & $.2 \%$ Petrostep B-120 & 2.0 & 9.5 \\
\hline Hepler & $.2 \%$ Petrostep B-120 & 2.12 & 9.5 \\
\hline Hepler & $.2 \%$ Petrostep B-120 & 2.25 & 9.5 \\
\hline Hepler & $.2 \%$ Petrostep B-120 & 2.38 & 9.5 \\
\hline Hepler & $.2 \%$ Petrostep B-120 & 2.50 & 9.5 \\
\hline Hepler & $.3 \%$ Petrostep B-120 & 1.0 & 9.5 \\
\hline Hepler & $3 \%$ Petrostep B-120 & 1.5 & 9.5 \\
\hline Hepler & $.3 \%$ Petrostep B-120 & 2.0 & 9.5 \\
\hline Hepier & $.3 \%$ Petrostep B-120 & 2.5 & 9.5 \\
\hline Hepler & $.3 \%$ Petrostep B-120 & 3.0 & 9.5 \\
\hline Hepler & $.4 \%$ Petrostep B-120 & 1.0 & 9.5 \\
\hline Hepler & $.4 \%$ Petrostep B-120 & 1.5 & 9.5 \\
\hline Hepler & $.4 \%$ Petrostep B-120 & 2.0 & 9.5 \\
\hline Hepler & $.4 \%$ Petrostep B-120 & 2.5 & 9.5 \\
\hline Hepler & $.4 \%$ Petrostep B-120 & 3.0 & 9.5 \\
\hline Hepler & $.4 \%$ Neodol $25-3$ & 0.0 & 9.5 \\
\hline Hepler & $.4 \%$ Neodol $25-3$ & 0.5 & 9.5 \\
\hline Hepler & $4 \%$ Neodol $25-3$ & 1.0 & 9.5 \\
\hline Hepler & $.4 \%$ Neodol $25-3$ & 1.5 & 9.5 \\
\hline Hepler & $.4 \%$ Neodol $25-3$ & 2.0 & 9.5 \\
\hline Hepler & $.4 \%$ Neodol $25-3$ & 3.0 & 9.5 \\
\hline
\end{tabular}




\begin{tabular}{|c|c|c|c|}
\hline Oil & Surfactant & $\mathrm{NaCl}, \%$ & $\mathrm{pH}$ \\
\hline Hepler & $.4 \%$ Neodol 25-3 & 5.0 & 9.5 \\
\hline Hepler & $.4 \%$ Neodol $25-3 S$ & 0.0 & 9.5 \\
\hline Hepler & $.4 \%$ Neodol $25-3 S$ & 0.5 & 9.5 \\
\hline Hepler & $.4 \%$ Neodol $25-35$ & 1.0 & 9.5 \\
\hline Hepler & $.4 \%$ Neodol $25-3 \mathrm{~S}$ & 1.5 & 9.5 \\
\hline Hepler & $.4 \%$ Neodol $25-3 \mathrm{~S}$ & 2.0 & 9.5 \\
\hline Hepler & $.4 \%$ Neodol $25-3 S$ & 3.0 & 9.5 \\
\hline Hepler & $.4 \%$ Neodol $25-3 S$ & 5.0 & 9.5 \\
\hline Hepler & $.4 \%$ Neodol $91-2.5$ & 0.0 & 9.5 \\
\hline Hepler & $.4 \%$ Neodol $91-2.5$ & 0.5 & 9.5 \\
\hline Hepler & $.4 \%$ Neodol 91.2 .5 & 1.0 & 9.5 \\
\hline Hepler & $.4 \%$ Neodol $91-2.5$ & 1.5 & 9.5 \\
\hline Hepler & $.4 \%$ Neodol $91-2.5$ & 2.0 & 9.5 \\
\hline Hepler & $.4 \%$ Neodol $91-2.5$ & 3.0 & 9.5 \\
\hline Hepler & $.4 \%$ Neodol $91-2.5$ & 5.0 & 95 \\
\hline Hepler & $.4 \%$ Neodol $91-6$ & 0.0 & 9.5 \\
\hline Hepler & $.4 \%$ Neodo! $91-6$ & 0.5 & 9.5 \\
\hline Hepler & $.4 \%$ Neodol $91-6$ & 1.0 & 9.5 \\
\hline Hepler & $.4 \%$ Neodol $91-6$ & 1.5 & 9.5 \\
\hline Hepler & $.4 \%$ Neodol 91-6 & 2.0 & 9.5 \\
\hline Hepler & $.4 \%$ Neodol $91-6$ & 3.0 & 9.5 \\
\hline Hepler & $.4 \%$ Neodol 91-6 & 5.0 & 9.5 \\
\hline Hepler & $.4 \%$ Neodol $45-13$ & 0.0 & 9.5 \\
\hline Hepler & $.4 \%$ Neodol $45-13$ & 0.5 & 9.5 \\
\hline Hepler & $.4 \%$ Neodol $45-13$ & 1.0 & 9.5 \\
\hline Hepler & $4 \%$ Neodol $45-13$ & 1.5 & 9.5 \\
\hline Hepler & $.4 \%$ Neodol $45-13$ & 2.0 & 9.5 \\
\hline Hepler & $.4 \%$ Neodol $45-13$ & 3.0 & 9.5 \\
\hline Hepler & $.4 \%$ Neodol $45-13$ & 5.0 & 9.5 \\
\hline Hepler & $.2 \%$ Neodol 25-7 & 0.0 & 9.5 \\
\hline Hepler & $.2 \%$ Neodol 25-7 & 0.5 & 9.5 \\
\hline Hepler & $.2 \%$ Neodol $25-7$ & 1.5 & 9.5 \\
\hline Hepler & $.2 \%$ Neodol $25-7$ & 2.0 & 9.5 \\
\hline Hepler & $.2 \%$ Neodol $25-7$ & 3.0 & 9.5 \\
\hline
\end{tabular}




\begin{tabular}{|c|c|c|c|}
\hline Oil & Surfactant & $\mathrm{NaCl}, \%$ & $\mathrm{pH}$ \\
\hline Hepler & $.2 \%$ Neodol $25-7$ & 5.0 & 9.5 \\
\hline Hepler & $.4 \%$ Neodol $25-7$ & 0.0 & 9.5 \\
\hline Hepler & $.4 \%$ Neodol $25-7$ & 0.5 & 9.5 \\
\hline Hepler & $.4 \%$ Neodol $25-7$ & 1.0 & 9.5 \\
\hline Hepler & $.4 \%$ Neodol $25-7$ & 4.5 & 9.5 \\
\hline Hepler & $.4 \%$ Neodol $25-7$ & 2.0 & 9.5 \\
\hline Hepler & $.4 \%$ Neodol $25-7$ & 3.0 & 9.5 \\
\hline Hepler & $.4 \%$ Neodol $25-7$ & 5.0 & 9.5 \\
\hline Hepler & $.6 \%$ Nuodol $25-7$ & 0.0 & 9.5 \\
\hline Hepler & $.6 \%$ Neodol $25-7$ & 0.5 & 9.5 \\
\hline Hepler & $.6 \%$ Neodol $25-7$ & 1.0 & 9.5 \\
\hline Hepler & $.6 \%$ Neodol $25-7$ & 1.5 & 9.5 \\
\hline Hepler & $.6 \%$ Neodol $25-7$ & 2.0 & 9.5 \\
\hline Hepler & $.6 \%$ Neodol $25-7$ & 3.0 & 9.5 \\
\hline Hepler & $.6 \%$ Neodol $25-7$ & 5.0 & 9.5 \\
\hline Hepler & $.2 \%$ Neodol 25-9 & 0.0 & 9.5 \\
\hline Hepler & $.2 \%$ Neodol 25-9 & 0.5 & 9.5 \\
\hline Hepler & $.2 \%$ Neodol $25-9$ & 1.0 & 9.5 \\
\hline Hepler & $.2 \%$ Neodol $25-9$ & 1.5 & 9.5 \\
\hline Hepler & $.2 \%$ Neodol 25-9 & 2.0 & 9.5 \\
\hline Hepler & $.2 \%$ Neodol $25-9$ & 3.0 & 9.5 \\
\hline Hepler & $.2 \%$ Neodol $25-9$ & 5.0 & 9.5 \\
\hline Hepler & $.4 \%$ Neodol $25-9$ & 0.0 & 9.5 \\
\hline Hepler & $.4 \%$ Neodol 25-9 & 0.5 & 9.5 \\
\hline Hepler & $.4 \%$ Neodol $25-9$ & 1.0 & 9.5 \\
\hline Hepler & $.4 \%$ Neodol $25-9$ & 1.5 & 9.5 \\
\hline Hepler & $.4 \%$ Neodol $25-9$ & 2.0 & 9.5 \\
\hline Hepler & $.4 \%$ Neodol $25-9$ & 3.0 & 9.5 \\
\hline Hepler & $.4 \%$ Neodol $25-9$ & 5.0 & 9.5 \\
\hline Hepler & $.6 \%$ Neodol $25-9$ & 0.0 & 9.5 \\
\hline Hepler & $.6 \%$ Neodol $25-9$ & 0.5 & 9.5 \\
\hline Hepler & $.6 \%$ Neodol $25-9$ & 1.0 & 9.5 \\
\hline Hepler & $.6 \%$ Neodol 25-9 & 1.5 & 9.5 \\
\hline Hepler & $.6 \%$ Neodol $25-9$ & 2.0 & 9.5 \\
\hline
\end{tabular}




\begin{tabular}{|c|c|c|c|}
\hline Oil & Surtactant & $\mathrm{NaCl} \%$ & $\mathrm{pH}$ \\
\hline Hepler & $.6 \%$ Neodol $25-9$ & 3.0 & 9.5 \\
\hline Hepler & $.6 \%$ Neodol $25-9$ & 5.0 & 9.5 \\
\hline Hepler & $.2 \%$ Neodol 25-12 & 0.0 & 9.5 \\
\hline Hepler & $.2 \%$ Neodol $25-12$ & 0.5 & 9.5 \\
\hline Hepler & $.2 \%$ Neodol $25-12$ & 1.0 & 9.5 \\
\hline Hepler & $.2 \%$ Neodol 25-12 & 1.5 & 9.5 \\
\hline Hepler & $.2 \%$ Neodol $25-12$ & 2.0 & 9.5 \\
\hline Hepler & $.2 \%$ Neodol $25-12$ & 3.0 & 9.5 \\
\hline Hepler & $2 \%$ Neodol $25-12$ & 5.0 & 9.5 \\
\hline Hepler & $.4 \%$ Neodol $25-12$ & 0.0 & 9.5 \\
\hline Hepler & $.4 \%$ Neodol 25-12 & 0.5 & 9.5 \\
\hline Hepler & $.4 \%$ Neodol $25-12$ & 1.0 & 9.5 \\
\hline Hepler & $.4 \%$ Neodol $25-12$ & 1.5 & 9.5 \\
\hline Hepler & $.4 \%$ Neodol 25-12 & 2.0 & 9.5 \\
\hline Hepler & $.4 \%$ Neodol $25-12$ & 3.0 & 9.5 \\
\hline Hepler & $.4 \%$ Neodol $25-12$ & 5.0 & 9.5 \\
\hline Hepler & $6 \%$ Neodol 25-12 & 0.0 & 9.5 \\
\hline Hepler & $.6 \%$ Neodol 25-12 & 0.5 & 9.5 \\
\hline Hepler & $.6 \%$ Neodol $25-12$ & 1.0 & 9.5 \\
\hline Hepler & $.6 \%$ Neodol $25-12$ & 1.5 & 9.5 \\
\hline Hepler & $.6 \%$ Neodol $25-12$ & 2.0 & 9.5 \\
\hline Heprs: & $.6 \%$ Neodol 25-12 & 3.0 & 9.5 \\
\hline Hepler & $.6 \%$ Neodol $25-12$ & 5.0 & 9.5 \\
\hline
\end{tabular}



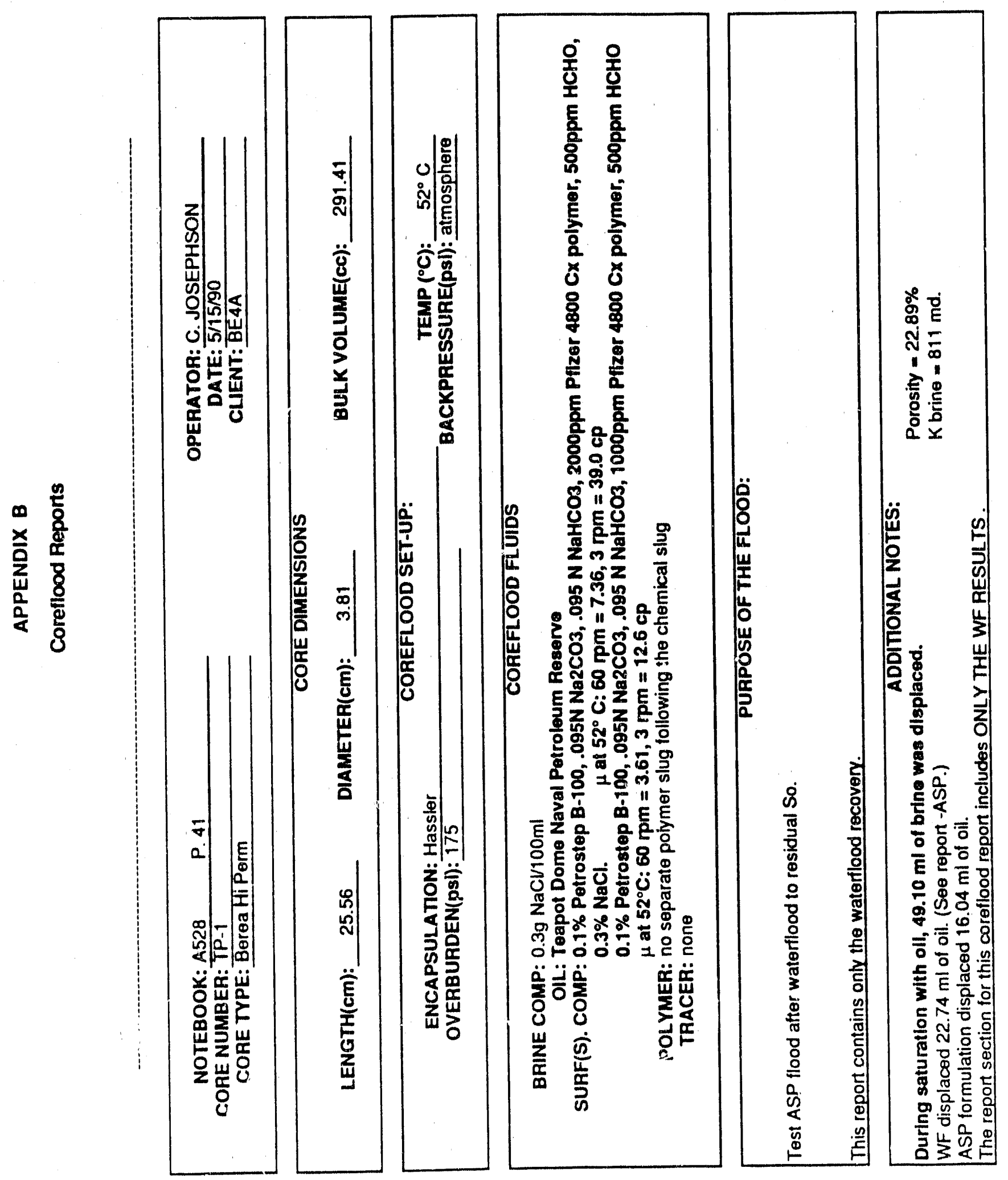


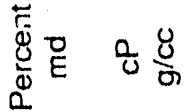

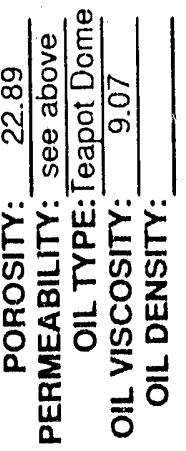

2

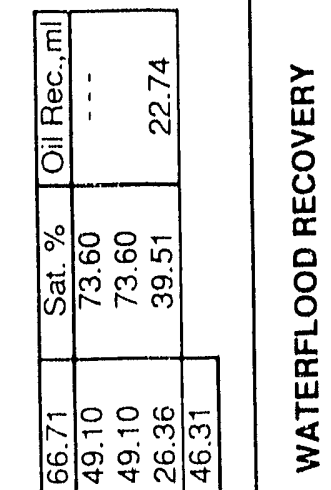

88.8 에 8.8.8nom

第

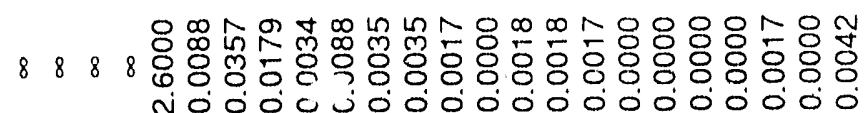

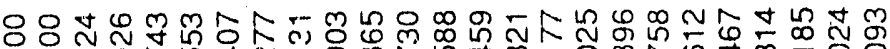

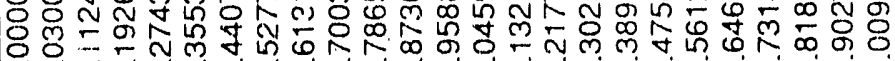

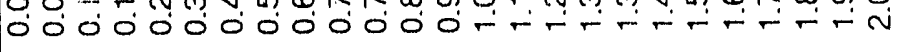

ه Ō

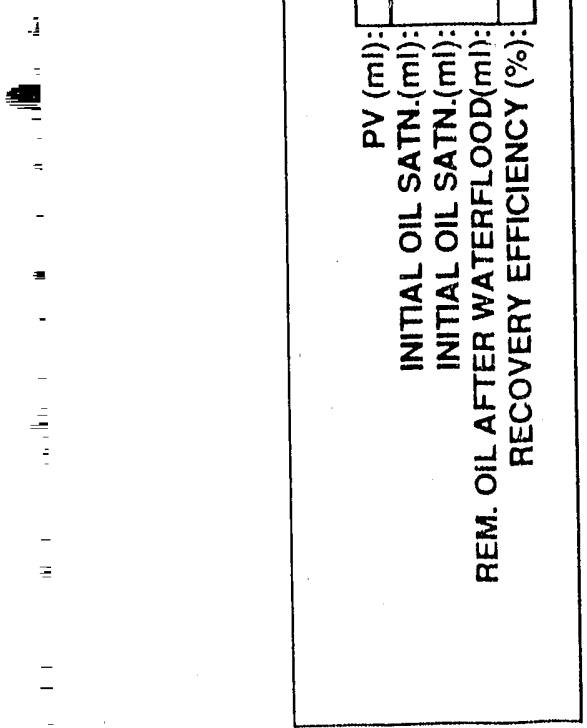

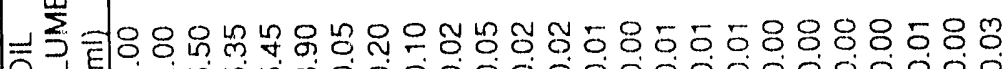
Oे

뜬

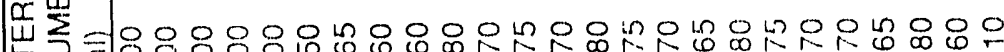

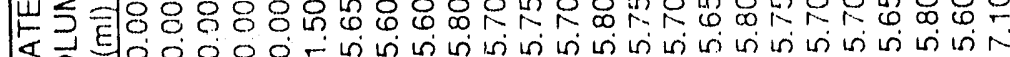
39

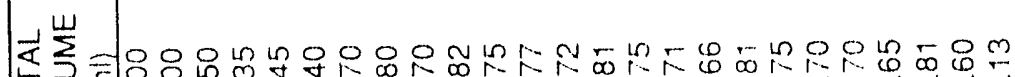

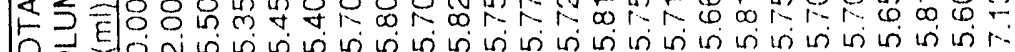
Q 


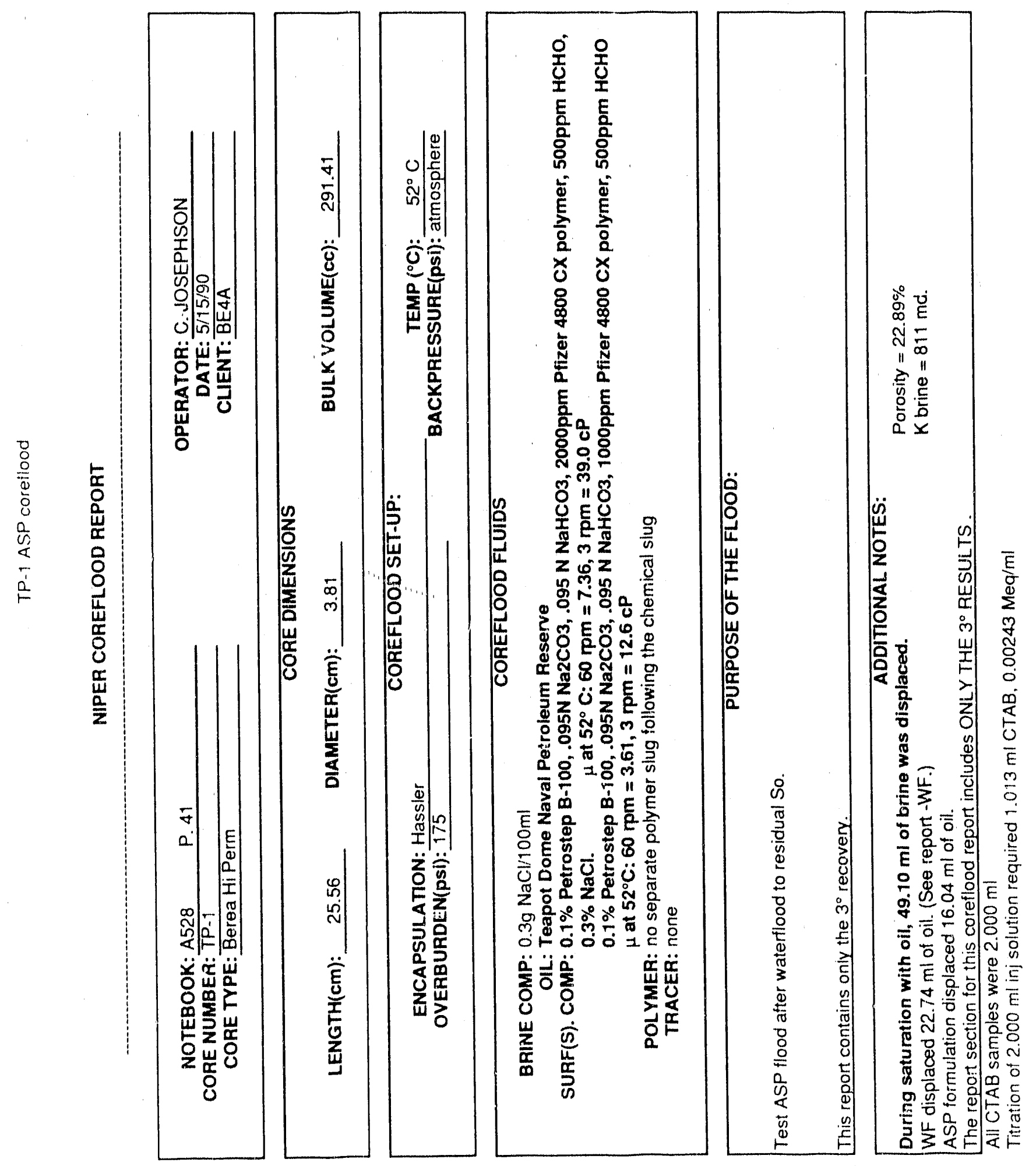



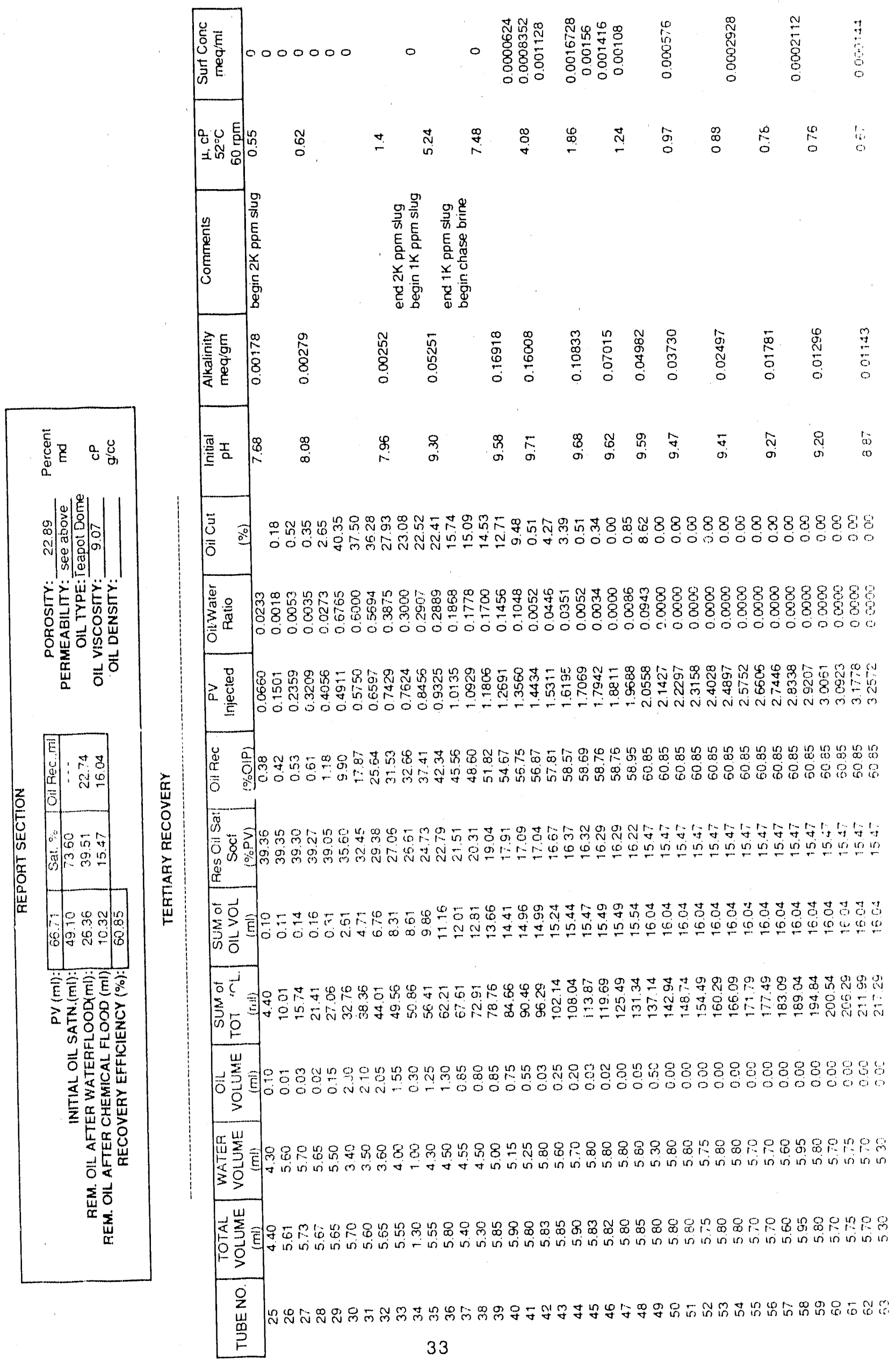


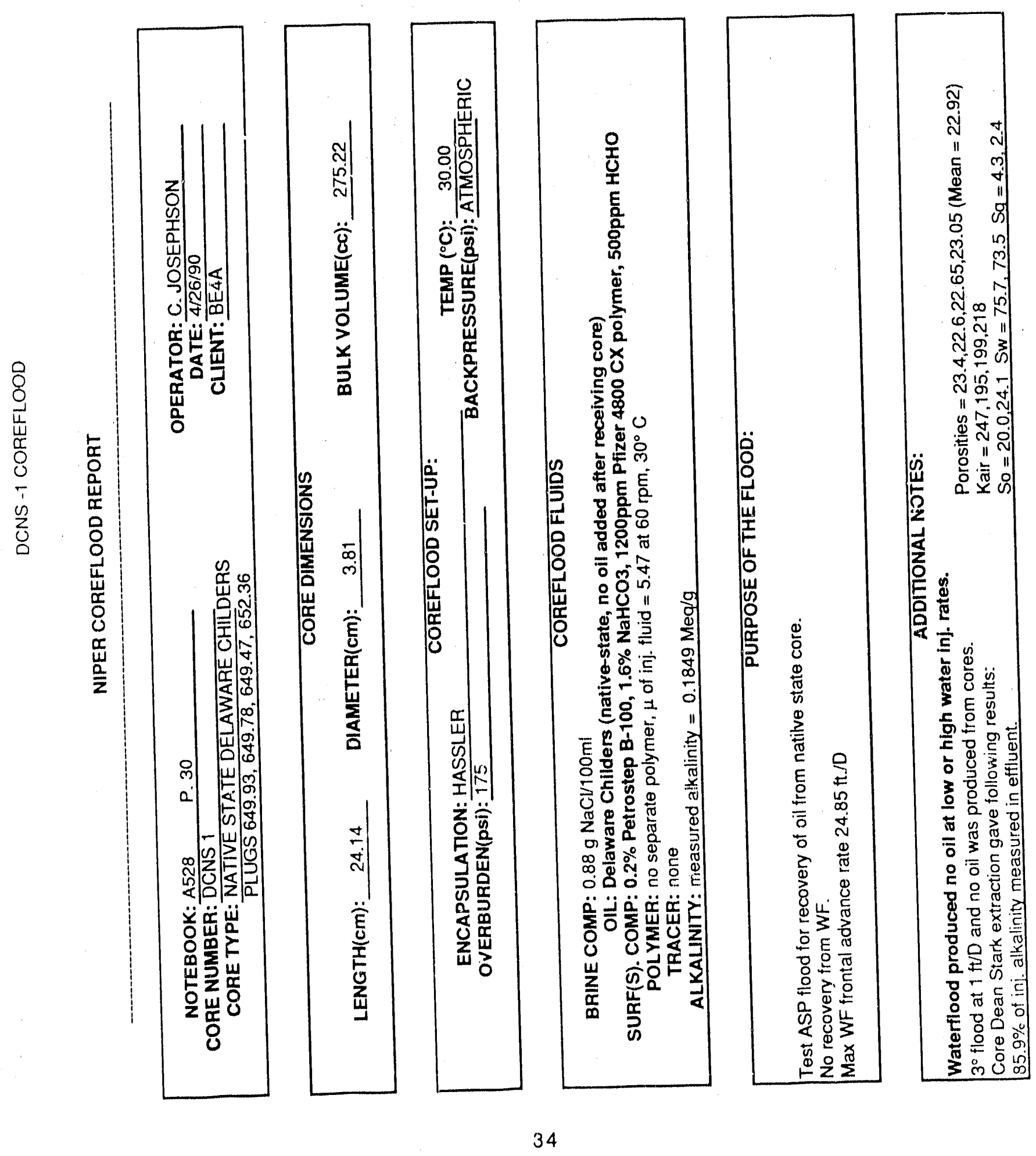


密

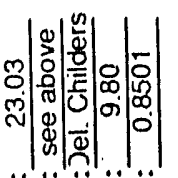

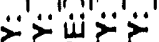
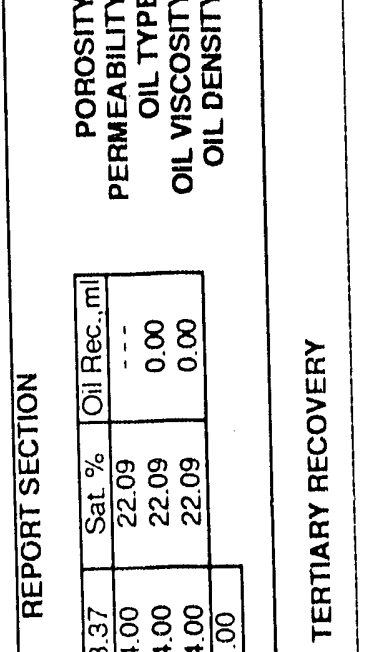

1

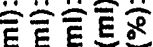

중잉ㅎㅇ

$<0$

謡曹

专制

级

之岳宁出

뜬

言乐

츤

뚣 离

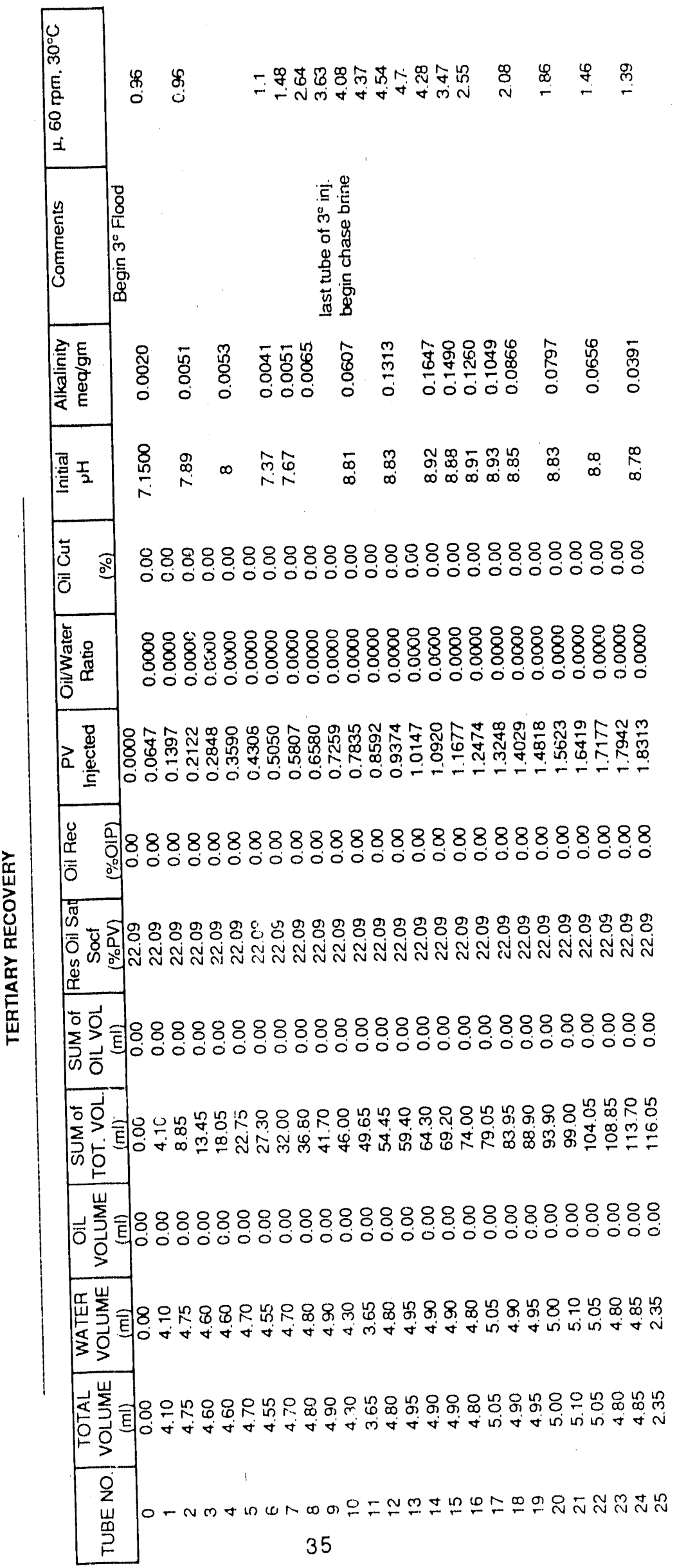




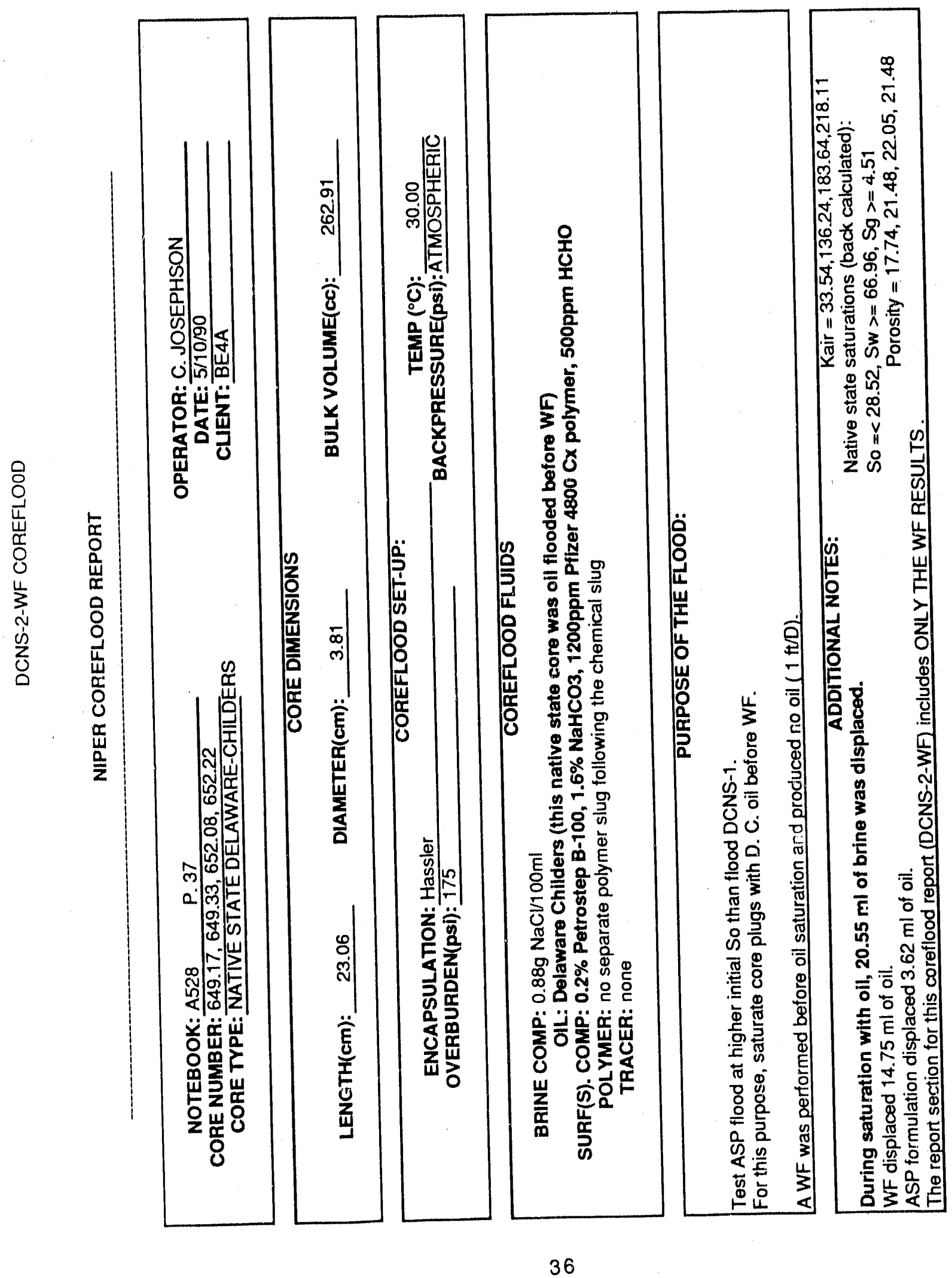



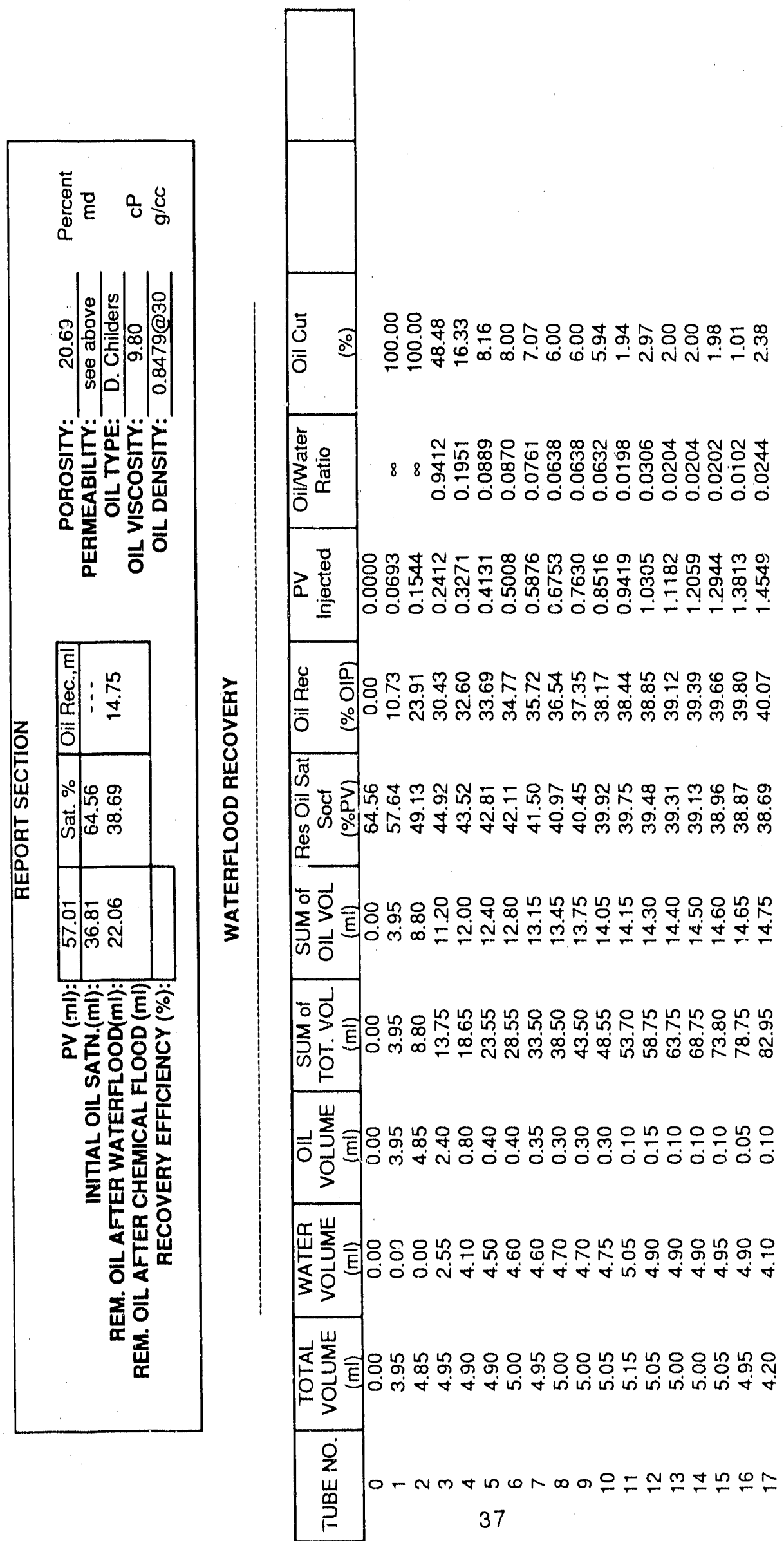

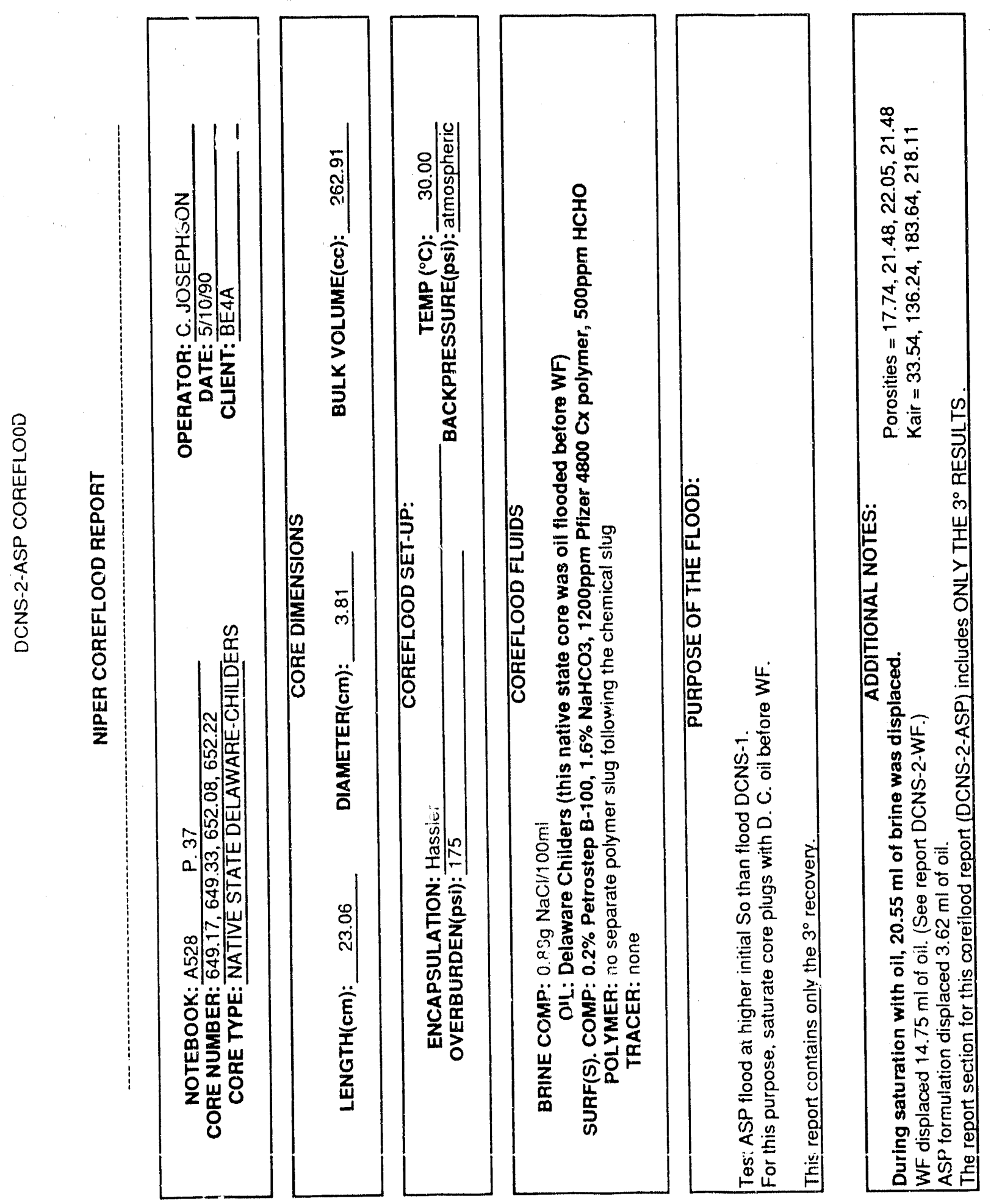

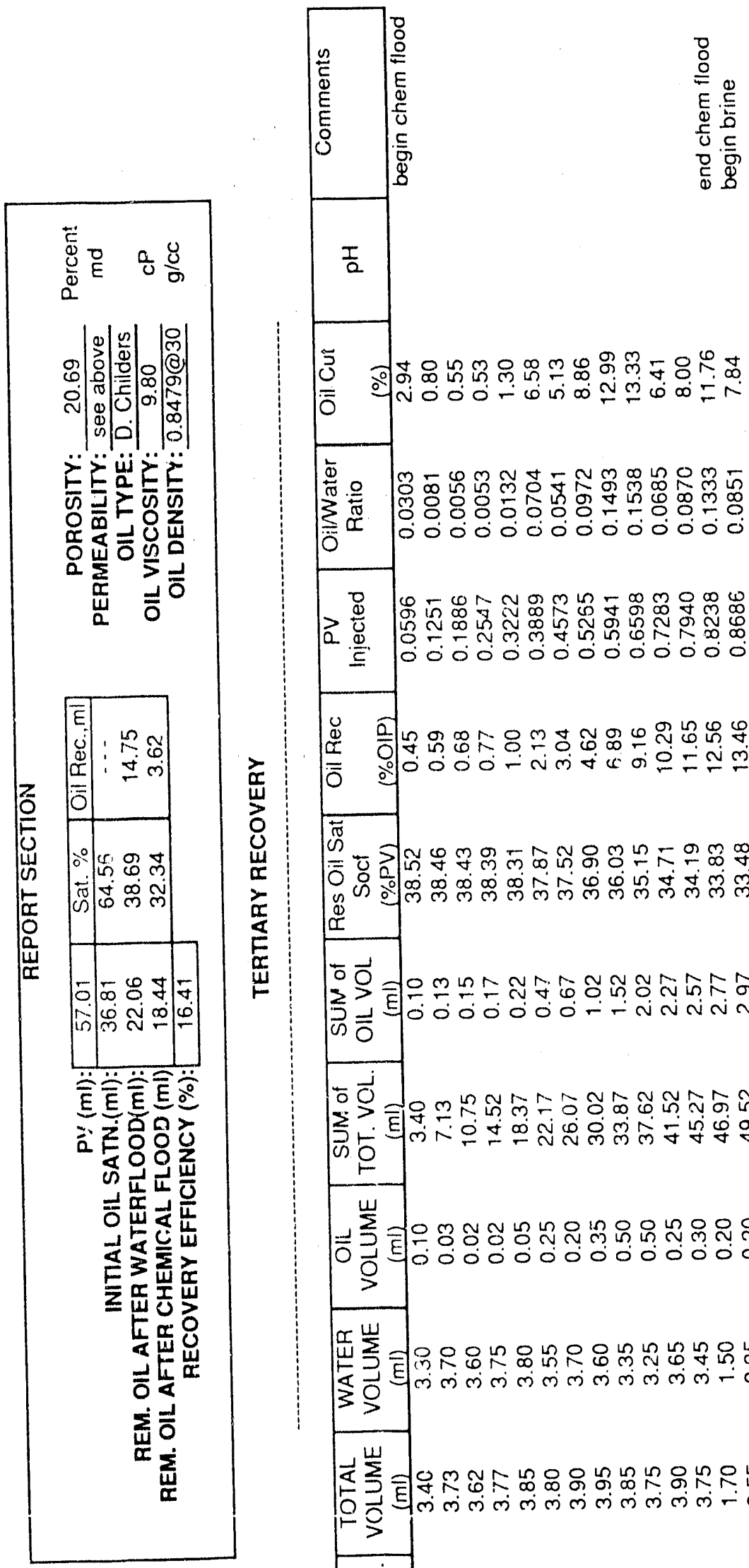

$\frac{T}{Q}$

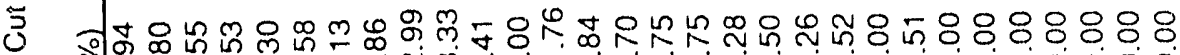
ô 离。 ô

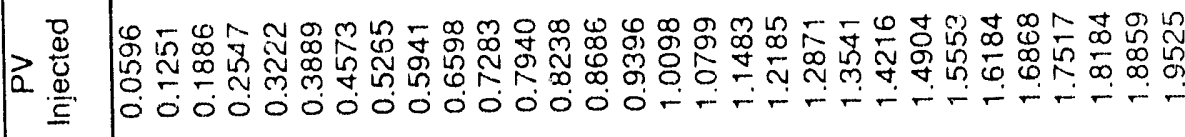

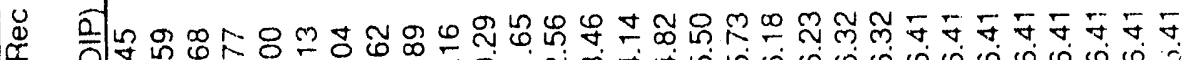
ố

ڤ ठ유. व

ㅁำ

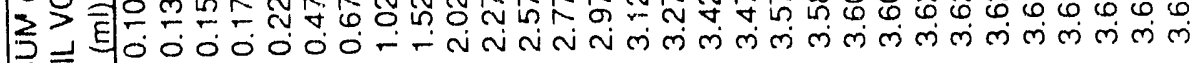
ऽ

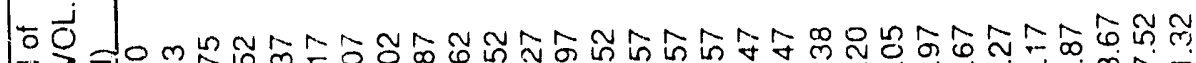

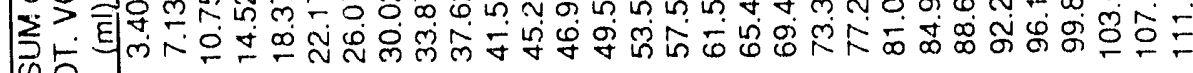
के

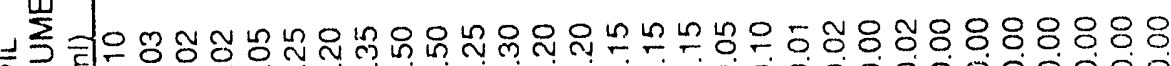

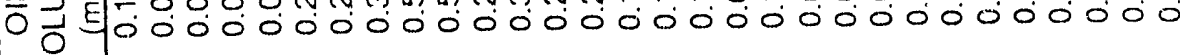

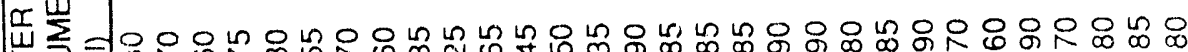

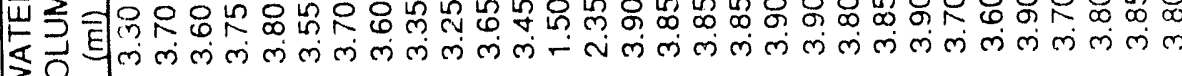

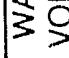

皮

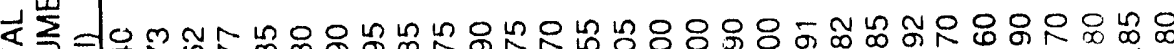

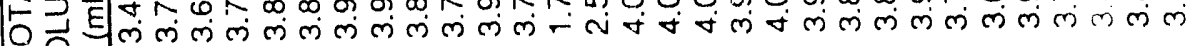
10 


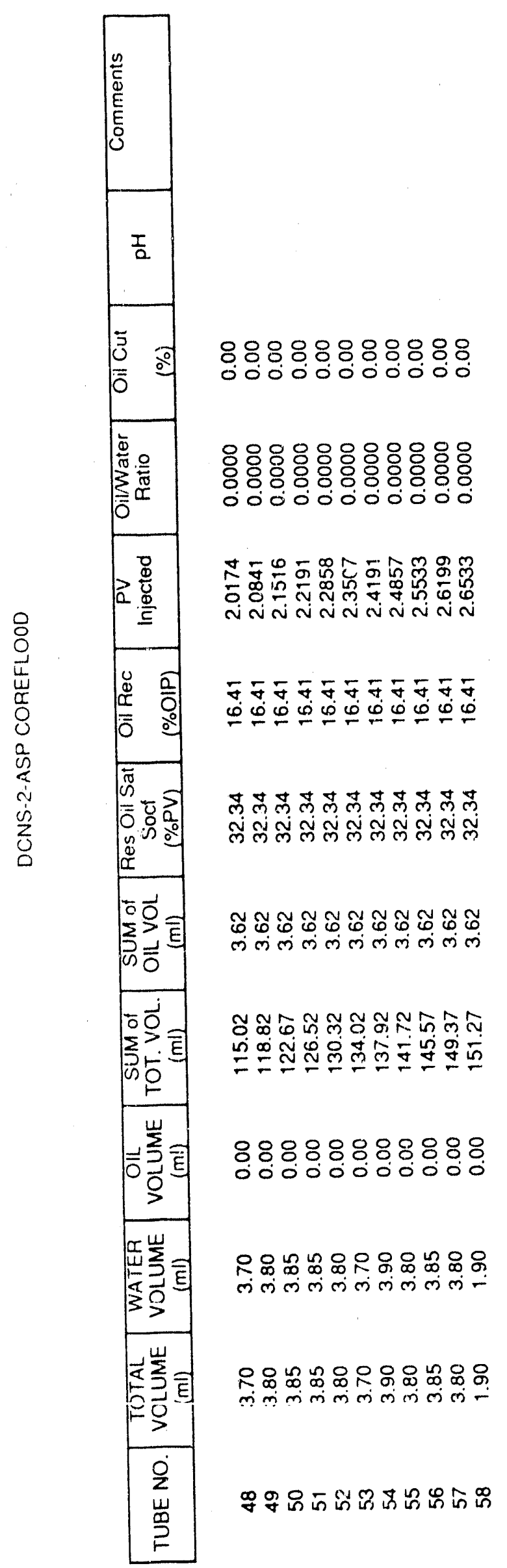




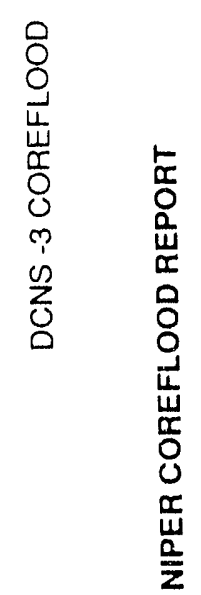

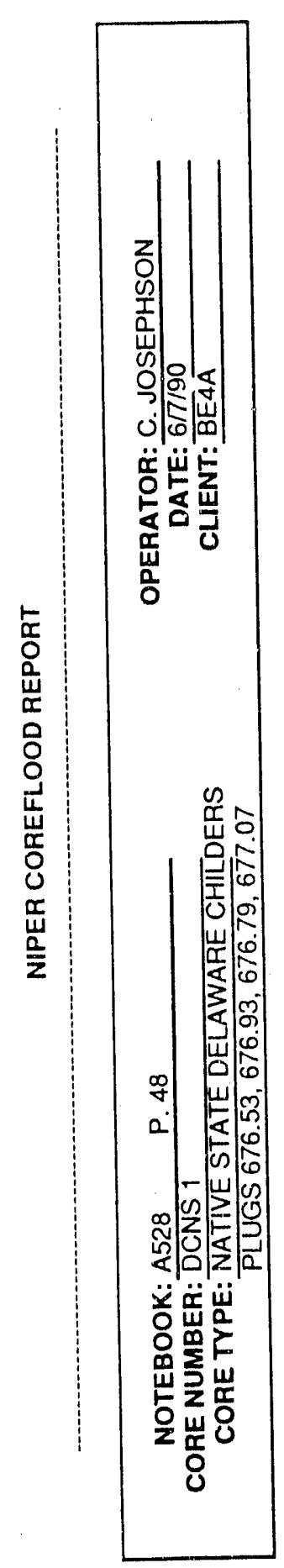

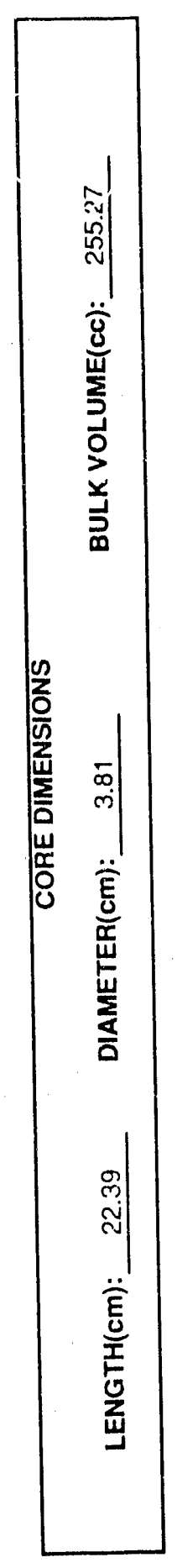
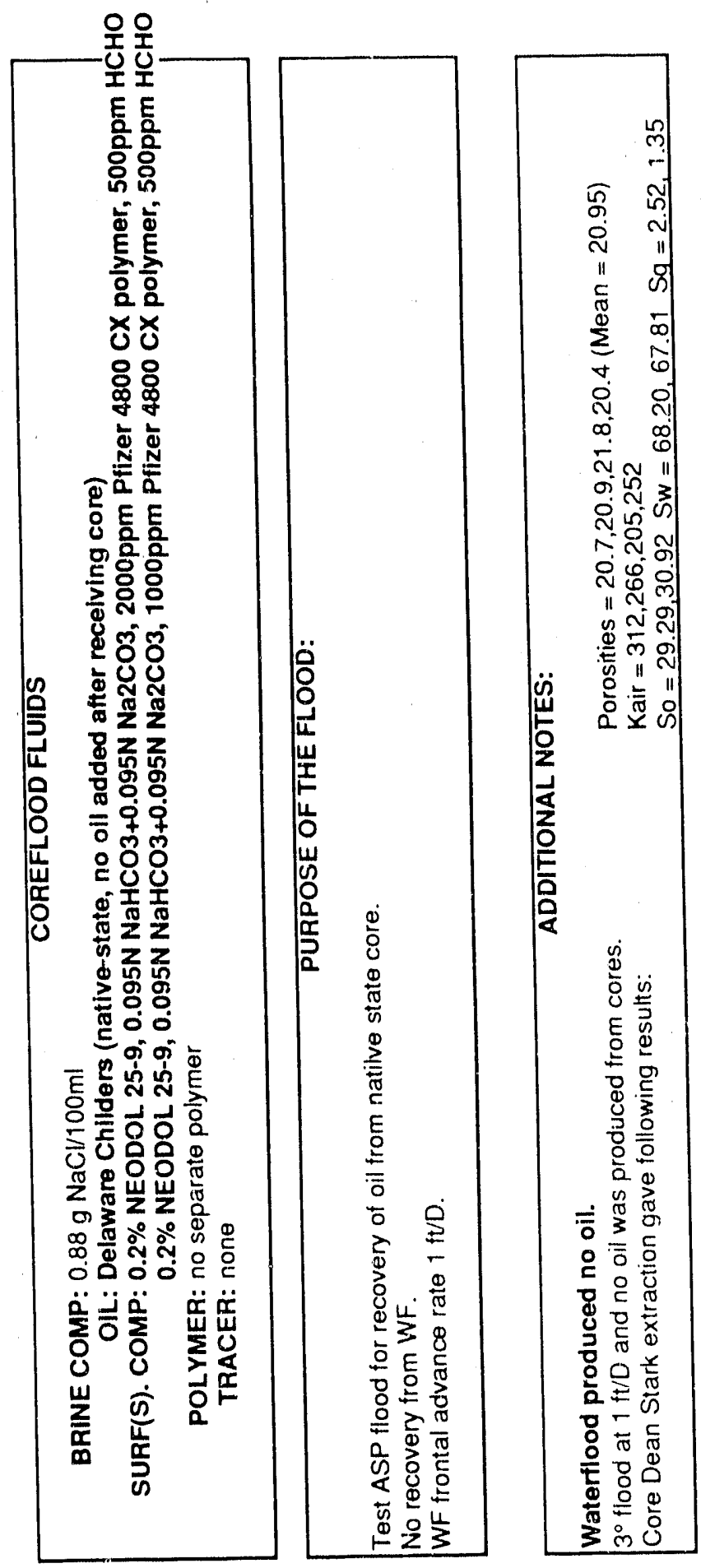
葱

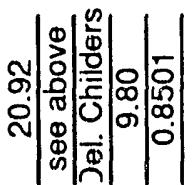

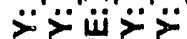

क足的

西员

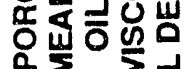
端 $\frac{1}{\overline{0}}$

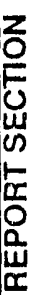

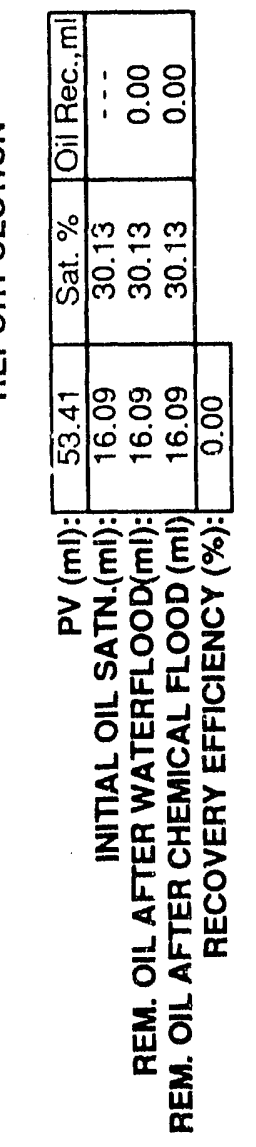

\begin{tabular}{|c|c|c|}
\hline 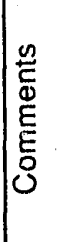 & 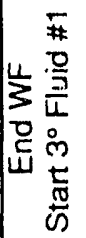 & 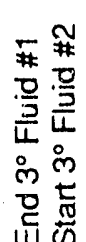 \\
\hline
\end{tabular}

I

ง ô o. o.

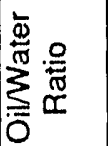

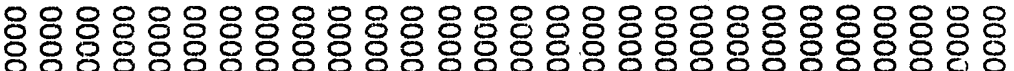

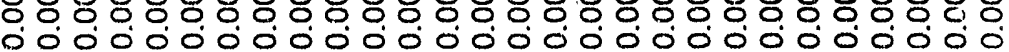

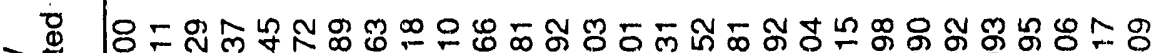

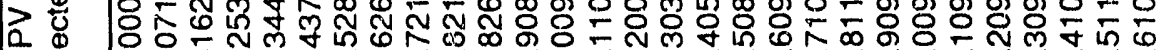

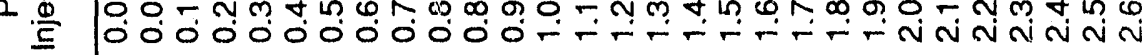

응요88888888888888888888888888 ố ॐ

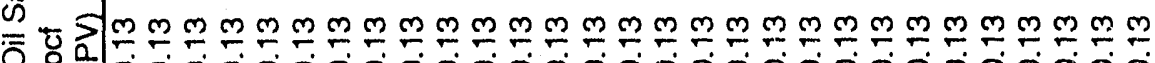

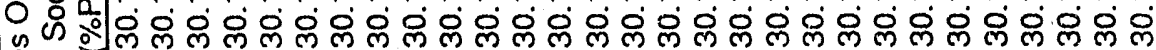
急

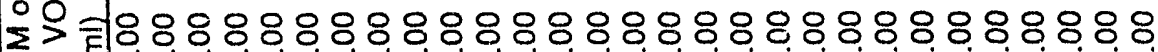
फ

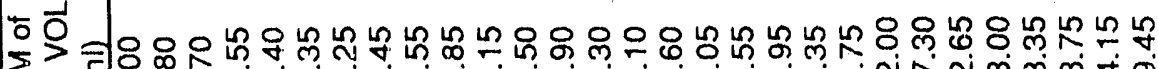
它国家 电

岁 ö ही $>$

叫崖

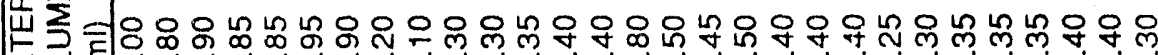
卉 \$?

远崖 O

1 崖 


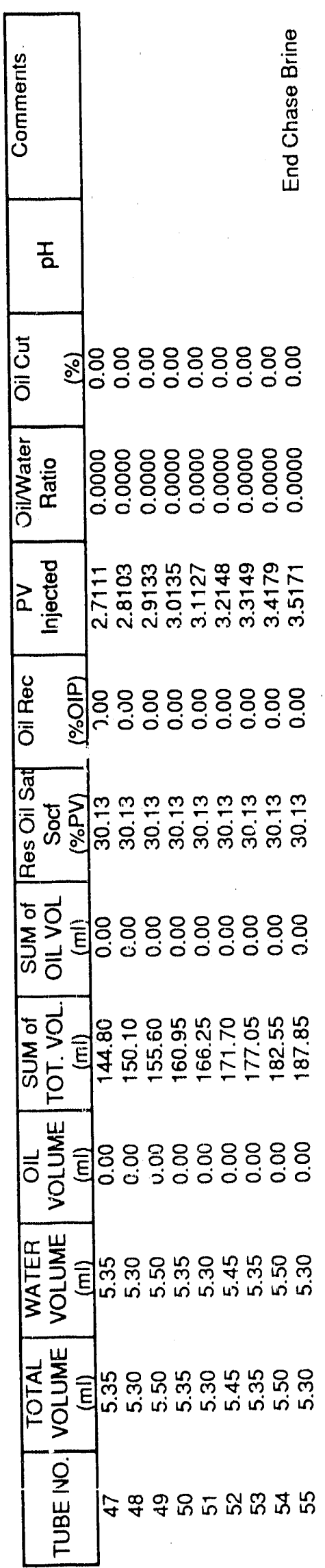

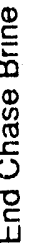

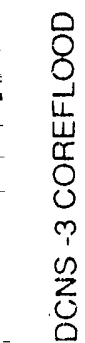

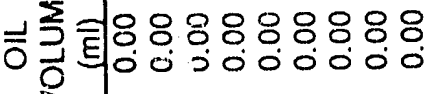

u

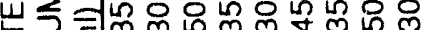

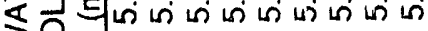

w

区 0 政 

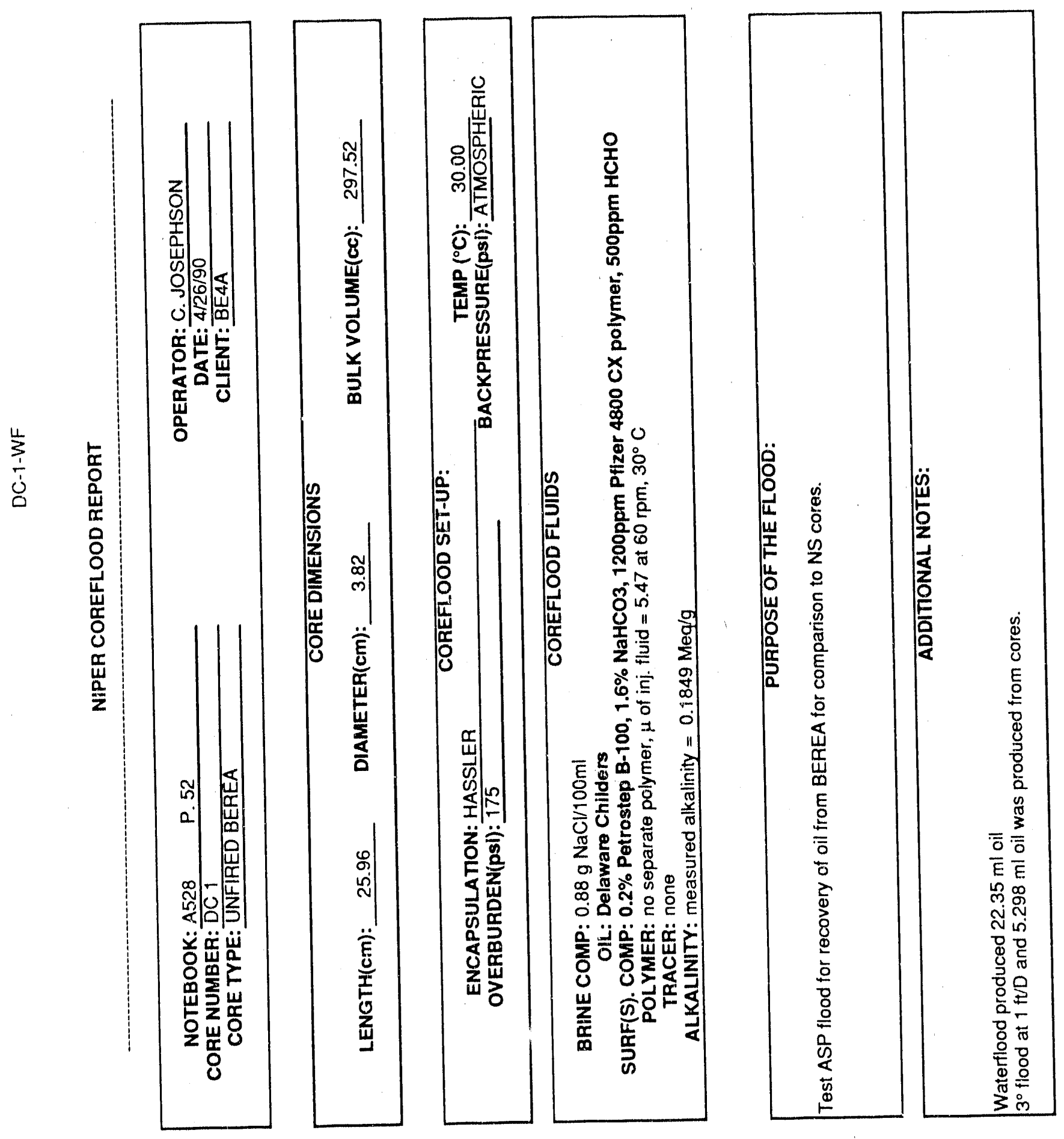

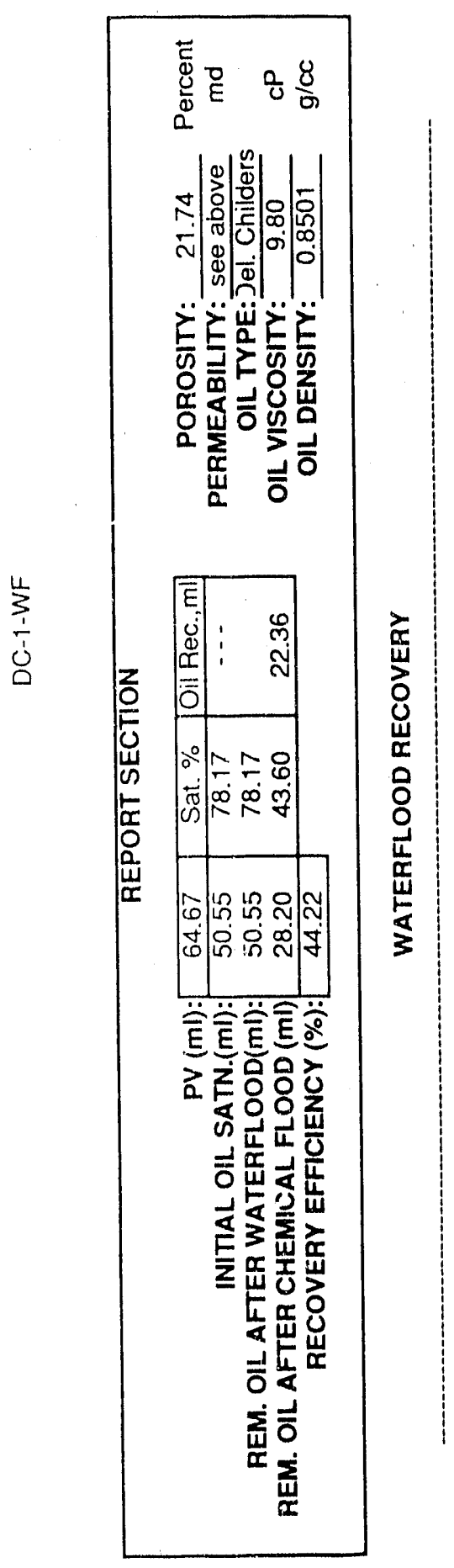

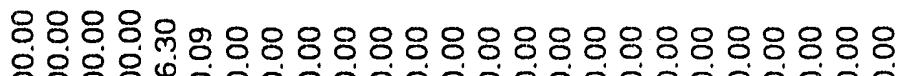

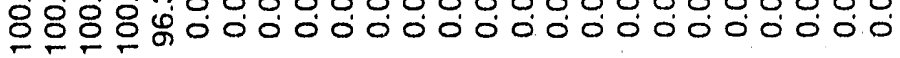

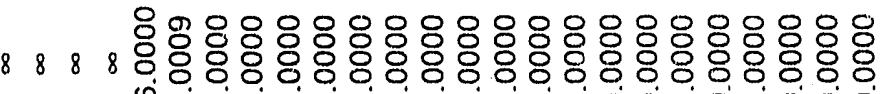

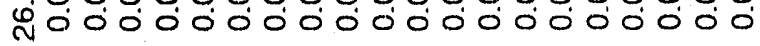

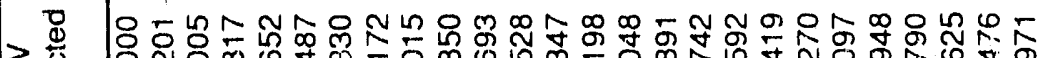

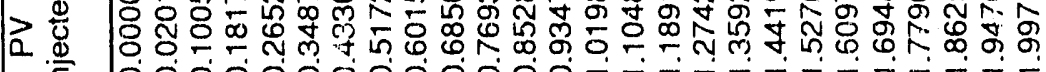
I 00000000000000.

离

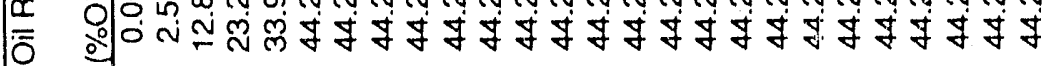
两

U一兀

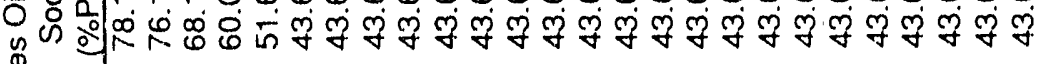
章

“ क๐

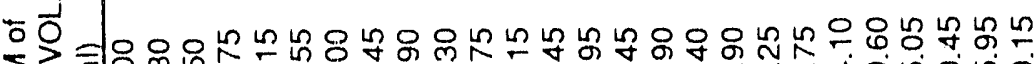

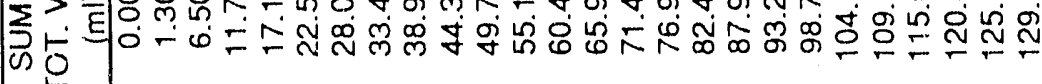

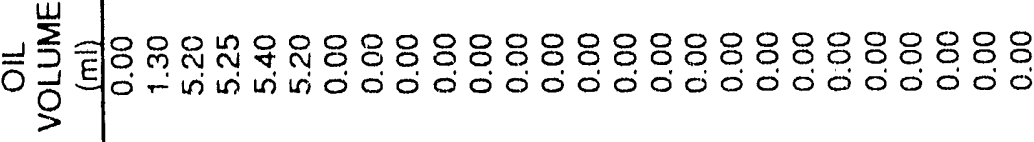

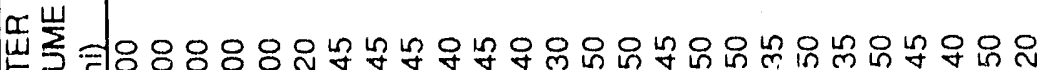
政

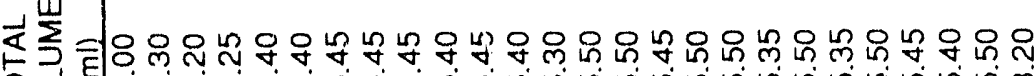

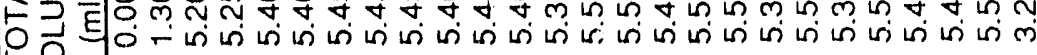
?

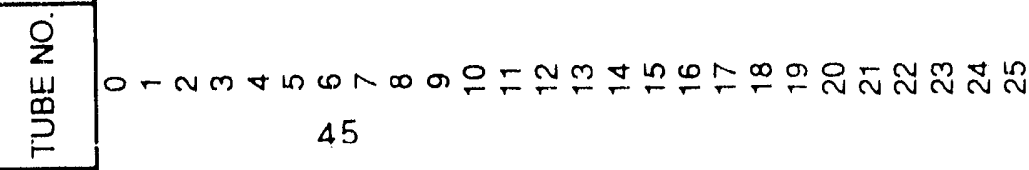




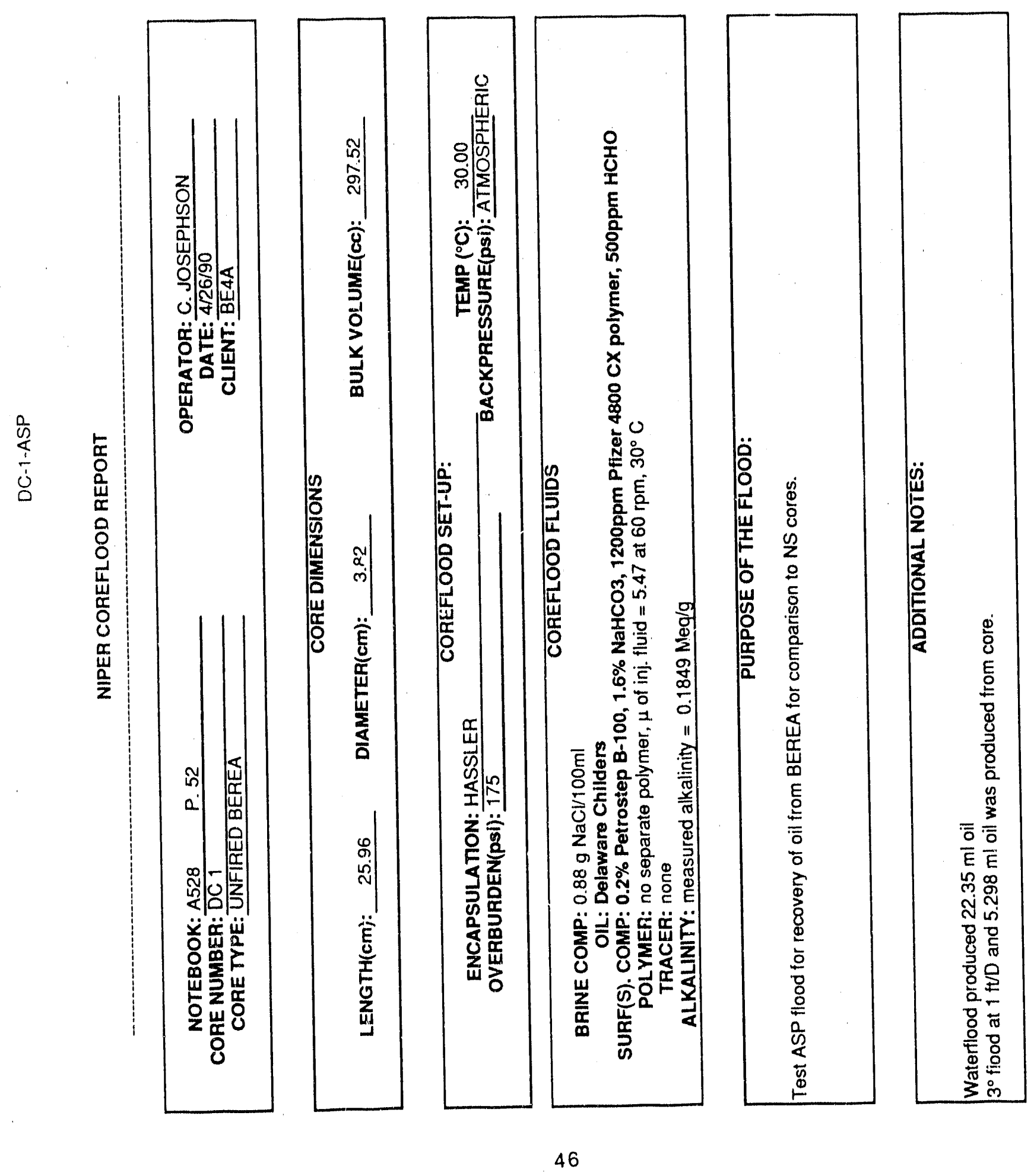




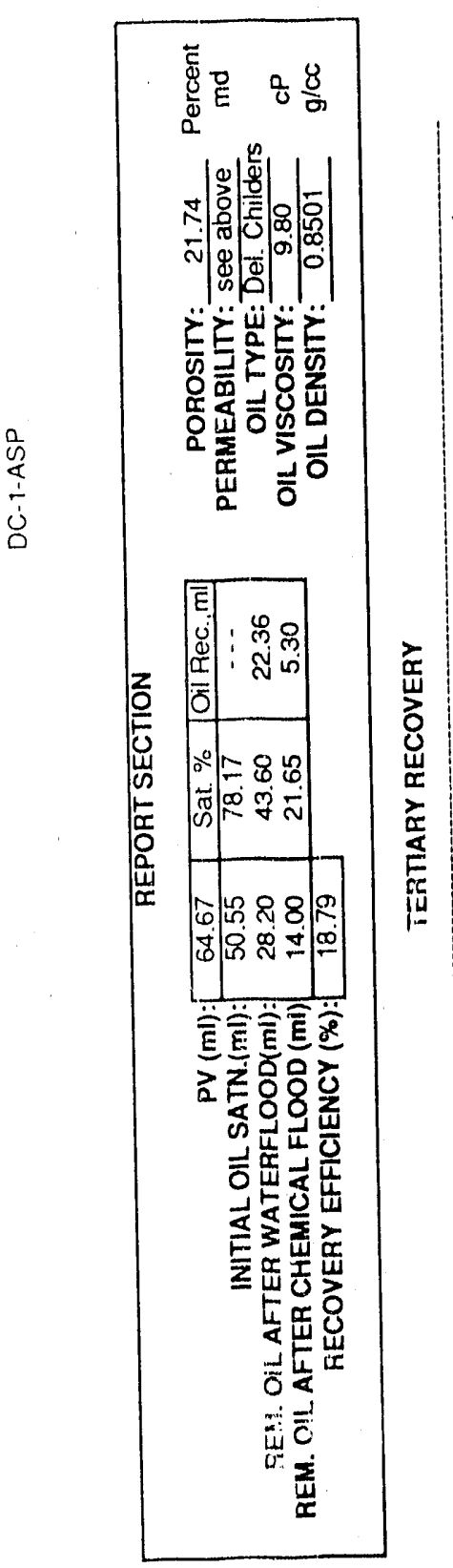



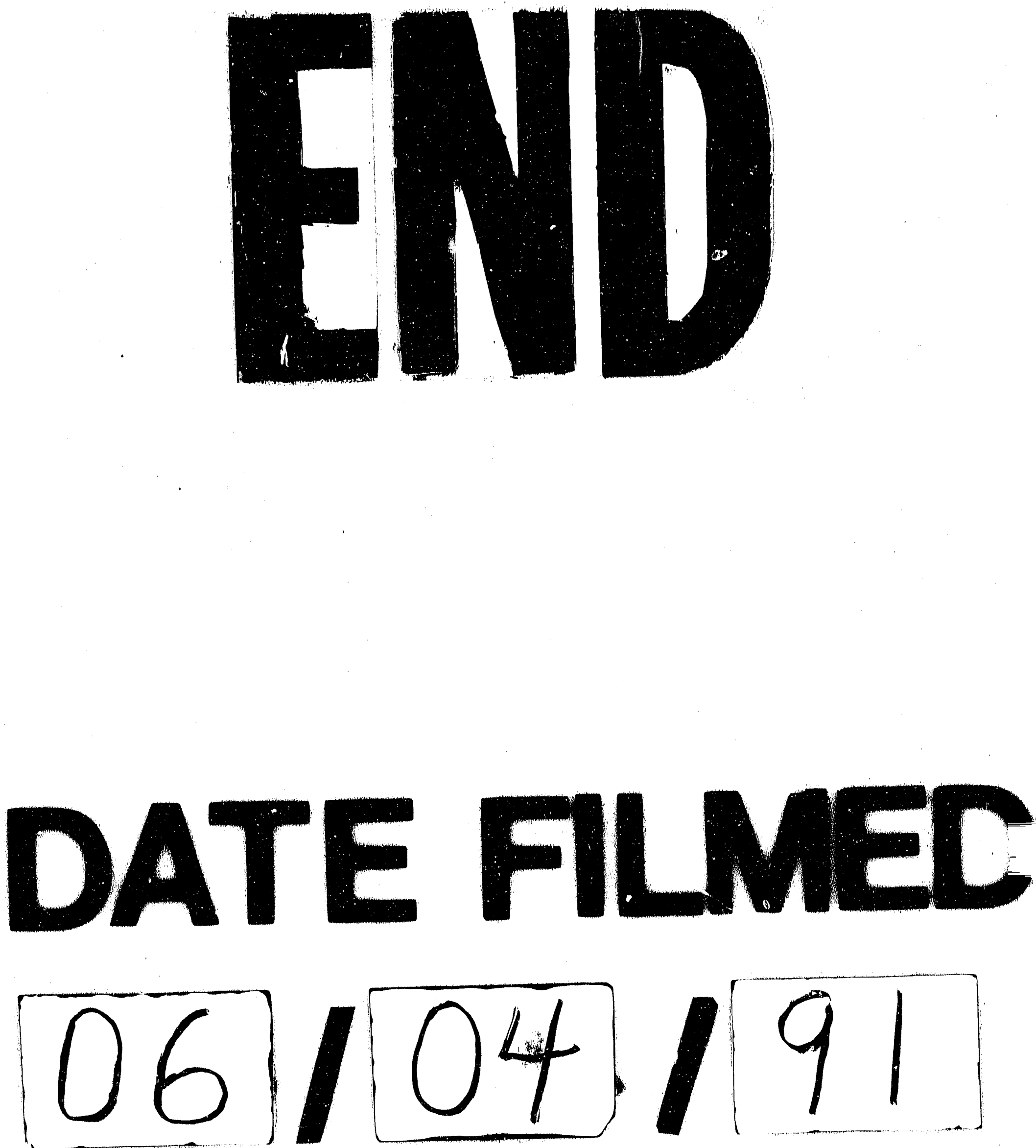
